\title{
Protective role of mRNA demethylase FTO on axon guiding molecules of nigro-striatal projection system in manganese-induced Parkinsonism
}

Zhipeng Qi

China Medical University

Jiashuo Li

China Medical University

Ke Zhang

China Medical University

Yanan Liu

China Medical University

Xinxin Yang

China Medical University

Minghui Li

China Medical University

Xianchao Du

China Medical University

Lei Zhang

China Medical University

Yi Wen

China Medical University

Bin Xu

China Medical University

Wei Liu

China Medical University

Zhaofa Xu

China Medical University

Yu Deng ( $\square$ dengyu.cmu@163.com )

China Medical University https://orcid.org/0000-0003-2292-2957

Research article

Keywords: Manganese, Parkinsonism, FTO, ephrin-B2, m6A, YTHDF2 
Posted Date: July 19th, 2021

DOl: https://doi.org/10.21203/rs.3.rs-710184/v1

License: (c) (i) This work is licensed under a Creative Commons Attribution 4.0 International License. Read Full License 


\section{Abstract \\ Background}

Parkinson's disease (PD) is a neurodegenerative disease caused by environmental and genetic factors. Manganese (Mn) exposure is a major environmental cause of PD. Cellular and molecular mechanism of Parkinsonism caused by $\mathrm{Mn}$ has not been explored clearly. In addition, patients with Mn-induced Parkinsonism show poor therapeutic response to levodopa. Therefore, there is need to explore the mechanisms underlying neurotoxicity of $\mathrm{Mn}$ exposure.

\section{Methods}

In short, we used SH-SY5Y cells and C57BL/6 mice to characterize Mn-induced Parkinsonism. We measured the behavioral, histological, ultrastructural and nigro-striatal projection system changes, cell viability, axon growth, and other target indicator levels, which led to the discovery of a novel mechanism of Mn-induced neurotoxicity.

\section{Results}

The findings of the current study showed that inhibition of fat mass and obesity-associated protein (FTO)-mediated demethylation of $\mathrm{N}^{6}$-methyladenosine $\left(\mathrm{m}^{6} \mathrm{~A}\right) \mathrm{mRNA}$ aggravates $\mathrm{Mn}$-induced motor dysfunction. Notably, FTO level is low in Mn exposure model mice and enhances occurrence of dyskinesia in mice. Over-expression of FTO reduces $\mathrm{m}^{6} \mathrm{~A}$ methylation in the key axon guiding molecules of nigro-striatal projection system, including ephrin-A5 and ephrin-B2. It increases ephrin-B2 mRNA decay through the $\mathrm{m}^{6} \mathrm{~A}$ reader YT521-B homology domain family proteins 2 (YTHDF2).

\section{Conclusions}

The findings of this study show that FTO, a $\mathrm{m}^{6} \mathrm{~A}$ demethylase, performs an indispensable function in Mninduced Parkinsonism. Notably, re-expression of FTO and ephrin-B2 improved motor dysfunction after Mn exposure.

\section{Background}

Parkinson's disease (PD) is a neurodegenerative disease caused by environmental and genetic factors [1]. Approximately 3 million PD cases are reported in China, and WHO predicts that this number will increase to 5 million by 2030 [2]. Most PD cases are sporadic cases caused by environmental factors, and only less than $10 \%$ of PD cases are caused by genetic factors [3]. Manganese (Mn) exposure is one of the major environmental risk factors that cause PD [4]. Mn is a quintessential component that is important 
for human health. It is an enzyme cofactor involved in neurotransmitter synthesis and in normal neuron and glial function [5]. Exposure to high levels of Mn can cause headache, lower limb weakness, cognitive impairment, muscle tone increase, tremor, gait difficulties and other symptoms similar to those of PD. The condition is known as manganism [6], or Mn-induced Parkinsonism [7, 8]. The 2019 Report on the State of the Ecology and Environment in China reported that $\mathrm{Mn}$ is one of the heavy metals that exceed sanitary requirements of ingesting water [9]. China has adopted active measures, such as clean production, use of gasoline with limited $\mathrm{Mn}$ and elimination of Mn from drinking water. However, environmental Mn pollution is still at an excessive level due to challenges in corporate governance, poor government supervision, and insufficient maintenance of equipment. In the central nervous system (CNS), excessive Mn mainly accumulates in the striatum $[10,11]$. Study reports that manganism is associated with the modifications of striatal dopamine (DA) pathway, which is mainly manifested by decrease in DA content [12]. However, studies on the molecular mechanisms for Mn induced dysregulation of DA levels are limited. In addition, specific mechanisms involved in motor dysfunction associated with simultaneous exposure to Mn have not been explored.

Accurate establishment of neural circuits involves the axon navigating the neurons to their target [13], which is essential for DA neurons of the substantia nigra to release DA after projecting to the striatum. Studies report that axon guidance regulation of dopaminergic neurons and spinal motoneurons plays important role in brain development $[14,15]$. The divergent member of the erythropoietin-producing hepatocyte receptor-interacting proteins (ephrins) mediate cell-cell communication thus regulating axon guidance and neural projection. Ephrins promotes developmental axon pathfinding by modulating actin cytoskeleton dynamics [16]. Researchers report that ephrins are abundantly expressed in the striatum [17]. Sieber et al [18] reported that ephrin signaling is important in normal connectivity and function of midbrain DA neurons. The present study postulated that $\mathrm{Mn}$ regulation of the motor function may be associated with the function of ephrins signaling. However, the specific molecular mechanisms were not elucidated.

Hundreds of RNA modifications have been reported, and N6-methyladenosine $\left(m^{6} A\right)$ is one of the most ubiquitous internal changes that regulate gene expression at the post-transcriptional level [19]. $\mathrm{m}^{6} \mathrm{~A}$ modification regulates several phases of RNA metabolism, such as RNA translation, decay and splicing $[20,21]$. The latest reported $m^{6} A$ demethylase FTO shows that $m^{6} A$ modifications can be dynamically regulated [22]. However, the targets and features of $\mathrm{m}^{6} \mathrm{~A}$ modification in CNS have not been explored. $\mathrm{m}^{6} \mathrm{~A}$ modification can regulate neuronal function such as motor function [23], axon regeneration [24], and synapse function [25]. In addition, Hess et a/ reported that inhibition of FTO gene impairs neuronal activity and motor function [26]. However, the function of $\mathrm{m}^{6} \mathrm{~A}$ eraser FTO on axon guiding molecules of nigro-striatal projection system in Mn-induced Parkinsonism pathogenesis has not been fully elucidated.

The findings of the current study show that FTO is implicated in regulation of motor function and mediation of axon guiding molecules against Mn-induced Parkinsonism in vitro and in vivo. These findings show the specific mechanism of Mn-induced motor dysfunction mediated by FTO and ephrins. 
Moreover, these findings show that re-expression of FTO and ephrin-B2 improve motor dysfunction after Mn exposure.

\section{Materials And Methods}

\section{Reagents and chemicals}

Manganese chloride $\left(\mathrm{MnCl}_{2} \cdot 4 \mathrm{H}_{2} \mathrm{O}\right)$ and actinomycin $\mathrm{D}$, and other chemical compounds were bought from Sigma Chemical Co. (Saint Louis, MO, USA). Cell Counting Kit-8 (CCK-8) was supplied with Transgen Institute of Biotechnology (Beijing, China). FD Rapid GolgiStain ${ }^{\text {TM }}$ kit was supplied by FD NeuroTechnologies (Ellicott City, MD, USA). Enzyme-linked immunosorbent assay (ELISA) kits of mice DA was acquired from Baolai Biotechnology Institute (Jiangsu, China). Ethyl ester derivative of MA (MA2, the FTO inhibitor) was a present from Professor Caiguang Yang of the Chinese Academy of Sciences. FluoroGold (FG) was purchased from Kaiji Biotechnology Co., Ltd. (Jiangsu, China). The adeno-associated virus 5 (AAV5)-FTO and AAV5-ephrin-B2 were purchased from Genecreate Biological Co., Ltd. (Wuhan, China). Lentiviral particles for over-expression of FTO (FTO-OE) were purchased from Hesheng Gene Technology Co., Ltd. (Beijing, China). Anti-m ${ }^{6}$ A antibody was bought from Synaptic Systems (USA, 202003). Protein-A bead was bought from Thermo Fisher (USA, 10002D). RNasin was provided by Promega Biotechnology Co., Ltd. (Beijing, China). Rabbit antibody of FTO, methyltransferase like 3 (METTL3), a-ketoglutaratedependent dioxygenase alkB homolog 5 (ALKBH5), YTH domain-containing family proteins $1 / 2$ (YTHDF1/2) were bought from Proteintech Group, Inc (Wuhan, China). Rabbit antibody of tyrosine hydroxylase (TH) was bought from Cell Signaling Technology, Inc. Rabbit antibody of METTL14, ephrinA1/3, ephrin-B1/3 were sold from ABclonal Biotechnology Co., Ltd. (Wuhan, China). Rat antibody of dopamine transporter (DAT), mouse antibody of ephrin-A5, ephrin-B2, Dopamine- and cAMP-regulated neuronal phosphoprotein 32 kDa (DARPP32) and GADPH were offered from Santa Cruz Biotechnology, Inc (Santa Cruz, CA, USA). Mouse antibody of ephrin-A2/4 was bought from Boaosen Biotechnology Co., Ltd. (Beijing, China). Horseradish peroxidase (HRP) conjugated anti-rabbit, mouse and rat secondary antibody were provided by means of Boaosen Biotechnology Co., Ltd. (Beijing, China). Real-time quantitative PCR (RT-qPCR) kit and Trizol reagent were supplied by TaKaRa Biotechnology Co, Ltd (Dalian, China). Other chemical substances were supplied through neighborhood chemical suppliers. All chemical substances reagents have been analytical grade or the pharmaceutical grade.

\section{Animals}

The research was carried out on adult C57BL/ 6 mice ( $20 \pm 2 \mathrm{~g} ; \mathrm{N}=350$; Among them, 30 pregnant mice are needed for primary neuron culture) which have been bought from the Laboratory Animal Centre of China Medical University, Shenyang, China (SPF grade, certificate no. SCXK2013-0001). The mice were housed in plastic cages with 12-h light/dark cycle (temperature, $25^{\circ} \mathrm{C} \pm 1{ }^{\circ} \mathrm{C}$, humidity, $55 \% \pm 5 \%$ ). Water and Food were accessible to the mice. All experiments were performed following the care and use guidelines of laboratory animals by Institutional Animal Care and Use Committee of China Medical University. The study protocol conformed to the National Institutes of Health Guide for Care and Use of 
Laboratory Animals (NIH Publications No. 8023, revised 1978). Attempts were made to minimize the number of animals used and to reduce animal suffering.

Primary neuron and SH-SY5Y culture

Neonatal C57 BL/6 mice were decapitated with scientific scissors without use of an anesthetic. The cranium was opened with ophthalmic forceps after sterilization with $75 \%$ alcohol. D-Hank's buffer solution was added to the dissected striatal tissue, and routinely separated with surgical devices under a light microscope. The tissue was digested with $0.125 \%$ trypsin solution for 20-30 min, and diluted with Dulbecco's modified Eagle's medium (DMEM; Sigma-Aldrich, USA) containing 20\% fetal bovine serum (FBS). Isolated neurons were seeded into $60-\mathrm{cm}^{2}$ plastic tissue culture flasks precoated with poly-L-lysine after purification by filtration through a 200-mesh sieve. Cultures were maintained in $5 \% \mathrm{CO} 2 / 95 \%$ air at $37^{\circ} \mathrm{C}$. After cell attachment, DMEM medium was replaced with Neurobasal ${ }^{\mathrm{T}}$-A Medium supplemented with B27 (Life Technologies). Neurons were further purified by addition of cytosine arabinoside and cultured for $24 \mathrm{~h}(5 \mu \mathrm{M}$, Sigma-Aldrich). Primary cultures yielded more than $95 \%$ neurons, which was determined through NeuN antibody immunostaining after culturing for approximately 7 days.

SH-SY5Y cells were purchased from the National Centre for Cell Sciences of China. Cells were maintained in $5 \% \mathrm{CO} 2 / 95 \%$ air at $37^{\circ} \mathrm{C}$ and cultured with DMEM supplemented with $10 \% \mathrm{FBS}$, streptomycin, and penicillin.

Animal experiments

One hundred forty mice were randomly assigned to sixteen groups based on their weight, with 12 mice in each group. The first part included the control group, 12.5, 25, and $50 \mathrm{mg} / \mathrm{kg} \mathrm{MnCl} 2$ groups. The second part included the AAV5 negative control (NC) group, AAV5-FTO control group, AAV5-NC $+50 \mathrm{mg} / \mathrm{kg} \mathrm{MnCl} 2$ group, and AAV5-FTO $+50 \mathrm{mg} / \mathrm{kg} \mathrm{MnCl}_{2}$ group. The third part included the control group, $20 \mathrm{mg} / \mathrm{kg} \mathrm{MA2}$ control group, $50 \mathrm{mg} / \mathrm{kg} \mathrm{MnCl}_{2}$ group, and $20 \mathrm{mg} / \mathrm{kg} \mathrm{MA2}+50 \mathrm{mg} / \mathrm{kg} \mathrm{MnCl} 2$ group. The fourth part included the AAV5-NC group, AAV5-NC + $50 \mathrm{mg} / \mathrm{kg} \mathrm{MnCl} 2$ group, AAV5-NC + $20 \mathrm{mg} / \mathrm{kg} \mathrm{MA2} \mathrm{+} 50 \mathrm{mg} / \mathrm{kg}$ $\mathrm{MnCl}_{2}$ group, and AAV5-ephrin-B2 + $20 \mathrm{mg} / \mathrm{kg} \mathrm{MA2}+50 \mathrm{mg} / \mathrm{kg} \mathrm{MnCl}_{2}$ group. Mice in the control group received a subcutaneous (s.c.) injection of $0.9 \% \mathrm{NaCl}$ and intraperitoneal (i.p.) injection of $0.9 \% \mathrm{NaCl}$ after $2 \mathrm{~h}$. Mice in the $\mathrm{MnCl}_{2}$ groups received s.c. injections of $0.9 \% \mathrm{NaCl}$ and i.p. injections of $12.5,25$, and 50 $\mathrm{mg} / \mathrm{kg} \mathrm{MnCl} 2$ after $2 \mathrm{~h}$. Mice in the MA2 control group were administered with s.c. injections with 20 $\mathrm{mg} / \mathrm{kg} \mathrm{MA2}$, and i.p. injections of $0.9 \% \mathrm{NaCl}$ after $2 \mathrm{~h}$. Mice in the $20 \mathrm{mg} / \mathrm{kg} \mathrm{MA} 2+50 \mathrm{mg} / \mathrm{kg} \mathrm{MnCl}$ group received s.c. injections with $20 \mathrm{mg} / \mathrm{kg} \mathrm{MA2}$, and i.p. injections of $50 \mathrm{mg} / \mathrm{kg} \mathrm{MnCl}_{2}$ after $2 \mathrm{~h}$. The concentration of treatments were $5 \mathrm{~mL} / \mathrm{kg}$. Treatments were administered daily two weeks.

For AAV5 viral injection, mice were anaesthetized with $5 \%$ chloral hydrate and positioned on a stereotaxic apparatus. Bilateral holes were drilled into the cranium at $0.5 \mathrm{~mm}$ foreside and $₫ 2.8 \mathrm{~mm}$ outside the bregma for administration of treatments into the striatum regions. An AAV5 expressing either FTO or ephrin-B2 (AAV5-FTO or AAV5-ephrin-B2) or hrGFP (AAV5-NC) was obtained through stereotactic injection. 
A glass cannula stuffed with a virus was placed on the striatum $(-3.5 \mathrm{~mm})$, and $0.2 \mu \mathrm{L}$ virus was administered at a rate of $0.1 \mu \mathrm{L} / \mathrm{min}$. The scalp was then sealed. Follow-up exposure was carried out 10 days after virus injection, and then behavioral experiments or other tests were carried out.

After the behavioral experiment, all the mice were sacrificed through decapitation under anesthesia. Striatum of 20 mice in each group was separated in an ice bath. 4 out of the 20 mice were used for histological and ultrastructural analysis of the striatum. Among the other 16 mice from each group, 4 were used for the detection of $\mathrm{Mn}$ and DA levels. 2 were used for immunofluorescence detection. 2 were used for determination of ephrin-B2 $\mathrm{m}^{6} \mathrm{~A}$ mRNA expression, 2 for electrophysiological recording, and 2 mice were used for fluorogold retrograde tracing. Striatum for the other mice was used for determination of target mRNA level, protein, and other indicator levels.

Lentiviral generation and infection.

Lentiviral particles for over-expression of NC and FTO were purchased from Hesheng Gene Technology Co., Ltd. (Beijing, China). For over-expression of ephrin-B2, METTL3, METTL14, YTHDF1 or YTHDF2, cells were transfected with plasmids using lipofectamine 2000 (Sigma, USA) following the manufacturer's instructions. After 48-72 h of transfection, the virus-containing supernatant was obtained and used to infect target cells, followed by screening with puromycin (Solarbio, $2.5 \mu \mathrm{g} / \mathrm{mL}$ ) for 7 days.

Cells treatments

Cells were cultured in media for $24 \mathrm{~h}$ with $0,125,250$, and $500 \mu \mathrm{M} \mathrm{MnCl}_{2}$. In the 0 and $500 \mu \mathrm{M} \mathrm{MnCl}_{2}$ groups, cells were used for over-expression of FTO, ephrin-B2, YTHDF2, FTO + METTL3 + METTL14, FTO + ephrin-B2, and FTO + YTHDF1 or YTHDF2. In addition, For the MA2 intervention groups, cells were cultured in media for $24 \mathrm{~h}$ with $0 \mu \mathrm{M} \mathrm{MnCl}_{2}, 200 \mu \mathrm{M} \mathrm{MA2,}, 500 \mu \mathrm{M} \mathrm{MnCl}_{2}$, and $200 \mu \mathrm{M} \mathrm{MA2}$ (pretreated for $6 \mathrm{~h})+500 \mu \mathrm{M} \mathrm{MnCl}_{2}$. The relevant experiments were then carried out.

Cell viability analysis

The cells were seeded into 96 -well plate at $5 \times 10^{3} /$ well and cultured in $10 \%$ FBS containing DMEM for $24 \mathrm{~h}$. Then, cells were treated in $100 \mu \mathrm{L}$ of DMEM according to the above groups. After incubating for $24 \mathrm{~h}$, add $10 \mu \mathrm{L}$ of CCK-8 reagent to every well, and incubate for extra $4 \mathrm{~h}$. Absorbance of every well was measured at $450 \mathrm{~nm}$. Each well has two duplicate wells to confirm the reproducibility.

Automated observation of axon growth with the live cell imager

Cells and axon growth trends were observed using Lionheart FX Automated Live Cell Imager (BioTeK, USA). The relevant treatment was given to every group following the study design. The control group was used to adjust the photo parameters. The duration of observation was $24 \mathrm{~h}$, and data were recorded every hour.

Rotarod test 
Mice were positioned on a Rotary rod instrument (UGO 47650, Italy) and skilled for 5 min at the $10 \mathrm{rpm}$ speed for 3 days. For testing, mice were positioned on a rod that turned around accelerating velocity beginning with $5 \mathrm{rpm}$ and accelerating up to $30 \mathrm{rpm}$ in $60 \mathrm{~s}$. Experiments were performed three times.

\section{Forced running wheel test}

Mice were positioned on a wheel fatigue meter (YLS-10B, Yiyan, China) to explore their staying power capabilities. Mice were skilled at $30 \mathrm{rpm}$ for $10 \mathrm{~min}$, and the fatigue running distance was determined. The wheel fatigue meter was stopped if mice fail to run within $10 \mathrm{sec}$ after the electric shock $(1 \mathrm{~mA})$ and the wheel fatigue meter was started after mice rest for $30 \mathrm{sec}$. The experiments were performed in triplicates.

\section{Open field test}

The open field experimental analysis system for mice was provided by China Medical University. The mice were placed in the laboratory to adapt to the environment for 10 minutes. This experiment is performed in a quiet, low-light environment. The indoor temperature was maintained at about $26^{\circ} \mathrm{C}$. The mice were positioned in the open field and the mice activity was observed within 5 min. Observation indicators include total horizontal movement distance and horizontal movement speed. Clean up the labyrinth after the experiment of each mouse, and try to avoid external interference that will cause unnecessary adverse effects on the experimental results.

Gait analysis

In order to enable all mice to walk to the end of the runway at a uniform speed without external stimulation, the mice were trained for 3 days. Data was collected on the 4th day and recorded 3 times for each mouse. The collected data was analyzed with Cat Walk XT Version10.6, and the average value of each index was taken. The related indexes are run duration, average speed, swing speed, and maximum variation.

\section{Determination of Mn levels}

The inductively coupled plasma mass spectrometry (ICP-MS, Agilent 7700x, USA) was used for analysis of Mn levels in striatum of mice. Striatum was predigested, and $0.1,1,5,10,50$, and $100 \mu \mathrm{g} / \mathrm{L}$ series of Mn standard solutions were prepared for future use. The content of $\mathrm{Mn}$ in the striatum was then determined with internal standard method.

\section{Measurement of DA levels}

Total DA levels in the striatum were quantified using ELISA kits of mice DA (Baolai, Jiangsu, China) following the manufacturer's directions. The sample value within the detectable range was used for analysis. Experiments were performed in triplicates. 
Expression and localization of FTO and ephrin-B2 were determined in striatum and neurons, respectively, through immunofluorescence. In addition, immunofluorescence triple staining of TH, DARPP32 and DAT in striatum was used to explore whether nigro-striatal projection neurons were damaged. Samples were dehydrated with xylene and alcohol, and tissue sections were steamed with sodium citrate for antigen retrieval. Samples were blocked in $10 \%$ Goat serum for $30 \mathrm{~min}$ at $25^{\circ} \mathrm{C}$. Samples were then treated with rabbit antibody of FTO (1:100), mouse antibody of ephrin-B2 (1:100), rabbit antibody of TH (1:100), mouse antibody of DARPP32 (1:50), and rat antibody of DAT (1:50) overnight at $4{ }^{\circ} \mathrm{C}$. On the second day, after $1 \mathrm{~h}$ of rewarming and washing 3 times with phosphate buffered solution (PBS), samples were treated with goat anti-mouse IgG (1:100), goat anti-rabbit IgG (1:100), and goat anti-rat IgG (1:100) for $1 \mathrm{~h}$ at $25^{\circ} \mathrm{C}$. For immunofluorescence of FTO and ephrin-B2, samples were counterstained using 2-(4Amidinophenyl)-6-indolecarbamidine dihydrochloride (DAPI) for 5 min after washing 3 times with PBS. Then, samples were mounted with mounting medium for further study. Laser scanning confocal microscope (A1R, Nikon, Japan) was used to capture images.

Hematoxylin and eosin (HE) staining

After the mice were perfused with $4 \%$ paraformaldehyde, the striatum tissue was removed. The striatum of mice was serially dehydrated in xylene and ethanol. The striatum was sectioned at $5 \mu \mathrm{m}$ thickness after paraffin embedded. Then, HE staining was done for morphological observation with high resolution panoramic imaging system (CS2, Leica, Germany).

Golgi-cox staining

Brains of mice were removed quickly from the skull after euthanizing. After washing, the brains were stained with the FD Rapid GolgiStain ${ }^{\text {TM }}$ kit (MD, USA). Firstly, the brains were incubated in the impregnation solution ( $A$ and $B$ ) for 14-15 days. Afterwards, the brains were treated with Solution $C$ for the 48-72 h. Microtome Cryostat (1950, Leica, Germany) was used to cut $200 \mu \mathrm{m}$ slices. Slices were mounted on a gelatin-coated slides, then dehydrated, stained, and coverslipped. Then, dendritic spines was observed with high resolution panoramic imaging system (CS2, Leica, Germany).

Nissl staining

Tissue sections were sequentially stained with series alcohol dehydration. The sections were then treated with $1 \%$ thionine for $1 \mathrm{~h}$, then the samples were washed with distilled water. $70 \%$ alcohol color separation was performed for several sec to several minutes. The sections were dehydrated with $70 \%, 80 \%$, $95 \%$, and $100 \%$ alcohol, re-spectively, with 2 min for each. Next, the sections were washed with anhydrous ethanol twice (with $5 \mathrm{~min}$ for each time), followed by washing with xylene twice (with $10 \mathrm{~min}$ for each time). Finally, the sections were observed with high resolution panoramic imaging system (CS2, Leica, Germany).

Fluorogold retrograde tracing 
Two mice in each group were injected with $2 \%$ FG solution into the striatum via brain stereotaxic injection. After 5 days of survival, the mice were anesthetized and perfused with $4 \%$ paraformaldehyde solution. The brain was taken out and fixed with $4 \%$ paraformaldehyde solution for 4 hours. Then the brain tissue was placed in a $20 \%$ sucrose solution at $4^{\circ} \mathrm{C}$ overnight. The next day, freeze sectioning was performed, and the section thickness was $30 \mu \mathrm{m}$. The sections were washed with $0.01 \mathrm{mM}$ PBS and fixed in $4 \%$ paraformaldehyde for 10 min. After washing 3 times with PBS, samples were mounted with mounting medium for further study. Laser scanning confocal microscope (A1R, Nikon, Japan) was used to capture images.

\section{Electron microscopy studies}

After the mice were perfused with $4 \%$ paraformaldehyde, the striatum was fixed with $2.5 \%$ glutaraldehyde for $1 \mathrm{~h}$. A 1-mm-thick slice was made and fixed overnight. Postfixation of slice was carried out in 1\% OsO4 for electron microscopy observation. Then, tissues were embedded in spur resin after dehydrated in series of acetone. Blocks were photographed in a transmission electron microscope (JEM-1400-FLASH, Japan) after stained with uranyl acetate and lead citrate.

Electrophysiological recording of striatum slices

Spontaneous discharge frequency in the striatum was recorded in $300 \mu \mathrm{m}$ slices. Slices were cut using vibratome in a modified artificial cerebrospinal fluid (mACSF) saturated with $5 \% \mathrm{CO}_{2} / 95 \% \mathrm{O}_{2}$. Slices were then placed on an incubation chamber with normal ACSF and incubated at $25^{\circ} \mathrm{C}$ for at least $1 \mathrm{~h}$ before recording. Analysis was performed with a MED64 flat microelectrode array system (Alpha of Japan).

Western Blotting analysis

Total protein of striatum was extracted with RIPA buffer and protease inhibitors. BCA reagent was used for protein quantification. Proteins samples were transferred onto polyvinylidene difluoride (PVDF) membranes after gel electrophoresis. PVDF membranes were then blocked using $5 \%$ bovine serum albumin fraction $\mathrm{V}$ for $1 \mathrm{~h}$, then the membranes were incubated with primary antibody against FTO (1:500), METTL3 (1:1000), METTL14 (1:500), ALKBH5 (1:1000), YTHDF1 (1:2000), YTHDF2 (1:1000), ephrin-A1 (1:1000), ephrin-A2 (1:500), ephrin-A3 (1:1000), ephrin-A4 (1:500), ephrin-A5 (1:500), ephrin-B1 (1:1000), ephrin-B2 (1:1000), ephrin-B3 (1:500), and GAPDH (1:5000) overnight at $4^{\circ} \mathrm{C}$. In the next day, membranes were incubated with corresponding secondary antibodies for $1 \mathrm{~h}$ at $25^{\circ} \mathrm{C}$ after washing 3 times with Tris-buffered saline with $0.1 \%$ Tween 20 (TBST). Analysis was performed with the multifunctional imaging system (AZURE C500, USA). GAPDH was used as an internal standard.

\section{RT-qPCR assay}

Total RNA was dissolved in RNase-free water (TaKaRa) after extraction using the Trizol reagent (TransGen, Beijing, China). First strand cDNA was obtained from total RNA using reverse transcriptase Kit (TaKaRa) following manufacturer's instructions. RT-qPCR was performed using QuantStudio 6 Flex 
fluorescence quantitative PCR instrument (Thermo Fisher, USA). Primer sequences of FTO, METTL3, METTL14, ALKBH5, YTHDF1, YTHDF2, ephrin-A1, ephrin-A2, ephrin-A3, ephrin-A4, ephrin-A5, ephrin-B1, ephrin-B2, ephrin-B3, Grb4, GIT1, HPRT1, and $\beta$-actin for RT-qPCR analysis are presented in Supplementary Table 1. HPRT1 or $\beta$-actin genes were used as internal controls. Comparative CT method $\left({ }^{\triangle \triangle} \mathrm{CT}\right)$ was used to quantify the target genes. All experiments were performed in triplicates.

Quantifcation of $\mathrm{m}^{6} \mathrm{~A}$ in total RNA

The ELISA-based $\mathrm{m}^{6} \mathrm{~A}$ Quantitative Kit (Epigentek, P-9005-96) was used to quantify $\mathrm{m}^{6} \mathrm{~A}$ levels of total RNA (200 ng). In accordance to the manufacturer's instructions, quantifification was performed in triplicates.

Actinomycin D assay

Samples were treated with $2 \mu \mathrm{M}$ actinomycin D (Act-D, Sigma, USA) for 0,3 , and $6 \mathrm{~h}$. Cells were collected and RNA was isolated for RT-qPCR. HPRT1 gene was used as an internal control as HPRT1 mRNA does not bind to YTHDF2, is rarely affected by Act-D, and does not undergo $\mathrm{m}^{6} \mathrm{~A}$ modifications.

$m^{6}$ A-RT-qPCR

Total RNA was used for $\mathrm{m}^{6} \mathrm{~A}$-immunoprecipitation and $500 \mathrm{ng}$ of RNA was used as an input sample. 100 $\mu \mathrm{g}$ of RNA was diluted with $40 \mu \mathrm{IP}$ buffer $(0.05 \mathrm{M}$ Tris- $\mathrm{HCl}, 0.75 \mathrm{M} \mathrm{NaCl}, 0.5 \%$ Igepal, and RNase-free water) and treated with $\mathrm{m}^{6} \mathrm{~A}$ antibody (Synaptic Systems, Germany) for $3.5 \mathrm{~h}$ at $4^{\circ} \mathrm{C}$, Recombinant protein-A bead (Waltham, MA) containing BSA was added to the RNA solution and shaken at $4^{\circ} \mathrm{C}$ for $4 \mathrm{~h}$. The $\mathrm{m}^{6} \mathrm{~A}$ IP portion was eluted with elution buffer $\left(300 \mu \mathrm{L} 20 \mathrm{mM} \mathrm{CaCl}_{2}, 2 \mu \mathrm{L} \mathrm{RNasin}, 2 \mu \mathrm{L} \mathrm{RVC}\right.$, and 0.75 $\mu \mathrm{L} 20 \mathrm{mg} / \mathrm{mL}$ Proteinase $\mathrm{K}$ ) after washing three times with IP buffer. The collected total eluate was concentrated in an RNA concentrator to a final volume of $20 \mu \mathrm{L}$. The concentration of RNA was determined and reverse transcribed to cDNA. RT-qPCR was used to determine $m^{6} \mathrm{~A}$ levels of mRNA. Data were calculated using the \%input $=2^{(-\Delta \text { Ctnormalized RIP })}$ method.

\section{Statistical analysis}

Results were presented as means \pm standard deviations after measured at least three times. The SPSS 22 software was used to analysis all statistical. The one-way analysis of variance (ANOVA) followed by Bonferroni test were used to determined the differences between the means for multiple comparison. $P$ value of $<0.05$ or $P$-value of $<0.01$ were considered statistically significant.

\section{Results}

\section{Effect of FTO on Mn-induced parkinsonism}


To explore the role of FTO in Mn-induced striatal motor dysfunction, the level of $\mathrm{Mn}$ in normal striatum and $\mathrm{Mn}$-exposed striatum was determined by ICP-MS. The findings showed that levels of $\mathrm{Mn}$ in striatum increased significantly after Mn exposure compared with the control group (Fig. 1A). Further, mRNA and protein levels of FTO and other methylases in striatum and neurons were determined. Analysis showed that mRNA and protein levels of FTO were significantly downregulated after Mn exposure compared with the control group (Fig. 1B, C, F, and G). Notably, other methylases levels including METTL3/14, ALKBH5, and YTHDF1/2 were not significantly different after Mn exposure compared with the control group (Supplementary Fig. 1A-T). Immunofluorescence was used to determine specific FTO protein levels in striatum and neurons. Analysis showed that FTO level (Green) was significantly decreased after Mn exposure compared with the normal group (Fig. 1D, H). In addition, ${ }^{6} \mathrm{~A}$ ELISA was used to determine changes in total RNA ${ }^{6} \mathrm{~A}$ level in striatum and neurons after $\mathrm{Mn}$ exposure. The findings showed that the level of total RNA ${ }^{6} \mathrm{~A}$ in striatum and neurons increased significantly after $\mathrm{Mn}$ exposure compared with the control group (Fig. 1E, I). These findings indicate that FTO is downregulated in striatum and neurons after $\mathrm{Mn}$ exposure, resulting in significant increase in the level of total RNA $\mathrm{m}^{6} \mathrm{~A}$ in striatum. This implies that FTO plays an inhibitory role in Mn-induced motor dysfunction.

\section{Role of FTO in Mn-induced motor dysfunction and morphological analysis}

Effect of over-expression FTO or inhibition of FTO activity in the striatum on regulating the symptoms was explored to verify that $\mathrm{Mn}$-induced motor disorders were caused by down-regulation of FTO in the striatum. AAV5 were used to express FTO (AAV-FTO) or hrGFP (AAV-control) in the striatum through stereotactic injection (Supplementary Fig. 2A, B), resulting in selective re-expression in bilateral striatum (Fig. 2A and B, Supplementary Fig. 2C). In addition, activity of FTO was inhibited by intraperitoneal administration of MA2, a selective inhibitor of FTO. The results showed that treatment of MA2 did not affect FTO expression (Supplementary Fig. 2D and E). Re-expression of FTO in mice exposed to Mn significantly decreased total RNA $\mathrm{m}^{6} \mathrm{~A}$ levels, with no significant effect on levels of $\mathrm{Mn}$ in the striatum (Fig. 2C and Supplementary Fig. 3A). On the contrary, inhibition of FTO activity in mice exposed to Mn significantly increased total RNA $\mathrm{m}^{6} \mathrm{~A}$ levels, with no significant effect on levels of $\mathrm{Mn}$ in the striatum (Supplementary Fig. 2F and Supplementary Fig. 3K). Re-expression of FTO in striatum exposed to Mn significantly increased their endurance times and fatigue running distance (Fig. 2D and E). Furthermore, it improved the distance covered and speed in the open field (Fig. 2F and Supplementary Fig. 3B-D). In addition, it significantly improved mice gait, mean intensity, run duration, average speed, swing speed and maximum variation performances in gait tests (Fig. $2 \mathrm{G}$ and Supplementary Fig. 3E-J). On the contrary, motor function was damaged more severely after inhibition of FTO activity (Supplementary Fig. 2G-J and Supplementary Fig. 3L-T). These findings indicate that inhibition of FTO significantly reduces motor performances, implying that FTO plays a protective role in Mn-induced motor dysfunction.

Effects of Mn on striatum morphology were determined by HE staining. In the control group, the nucleus of striatum was stained clearly. The nucleus was round and giant with evident nucleoli (Fig. 2H). The 50 
$\mathrm{mg} / \mathrm{kg} \mathrm{MnCl}_{2}$ group (Fig. $2 \mathrm{H}$ ) showed significant interstitial vacuolation and cell swelling compared with the control group. Re-expression of FTO significantly improved neuropathological injury compared with the $50 \mathrm{mg} / \mathrm{kg} \mathrm{MnCl}_{2}$ group (Fig. $2 \mathrm{H}$ ). Nissl staining in the control group showed that Nissl bodies were clearly stained, arranged neatly and the number was normal (Fig. 2I). Analysis showed significant degeneration of Nissl bodies, deletion and lighter staining in the $50 \mathrm{mg} / \mathrm{kg} \mathrm{MnCl} 2$ group compared with the normal control group (Fig. 2I). Re-expression of FTO significantly alleviated deformation and deletion of Nissl bodies compared with the $50 \mathrm{mg} / \mathrm{kg} \mathrm{MnCl}_{2}$ group (Fig. 2l). Observation under an electron microscope showed that the nucleus of the control group was approximately round and the structure was normal (Fig. 2J). Neuronal nucleus pyknosis, organelle disappearance, swelling and degeneration were observed in the $50 \mathrm{mg} / \mathrm{kg} \mathrm{MnCl}_{2}$ group (Fig. 2J). Notably, re-expression of FTO significantly improved neuronal damage compared with the $50 \mathrm{mg} / \mathrm{kg} \mathrm{MnCl}$ group (Fig. 2J). Changes in dendritic density and/or morphology were investigated to explore the effects of $\mathrm{Mn}$ on axonal guidance regulates synaptic plasticity (Fig. 2K-L). Morphology of dendrites was significantly damaged and the density of total dendritic spines decreased significantly after exposure to $50 \mathrm{mg} / \mathrm{kg} \mathrm{MnCl}_{2}$ compared with normal control group (Fig. 2K-L). Re-expression of FTO significantly improved the morphology of dendrites and the density of total dendritic spines compared with the $50 \mathrm{mg} / \mathrm{kg} \mathrm{MnCl}_{2}$ group (Fig. 2K-L).

Spontaneous discharge activity reflects the function of striatal neurons. Acute brain slices from mice were used to record electrical signals through substrate embedded electrodes to explore the discharge activity of the striatum. A typical electrical signal obtained using a microelectrode is shown in Fig. $2 \mathrm{M}$. Individual spontaneous potential was recorded when the individual spontaneous potential exceeds the threshold $( \pm 0.02 \mathrm{mV})$. Neurons from the striatum of the control group showed normal spontaneous activity (Fig. 2M). The amplitude and frequency of spike waves decreased after treatment with $50 \mathrm{mg} / \mathrm{kg}$ $\mathrm{MnCl}_{2}$ compared with the control group (Fig. 2M). Re-expression of FTO significantly improved the damaged spontaneous discharge frequency compared with the $50 \mathrm{mg} / \mathrm{kg} \mathrm{MnCl} 2$ group.

On the contrary, the morphology was severely damaged and electrophysiological signals of striatum were significantly reduced after inhibition of FTO activity compared with over-expression of FTO

(Supplementary Fig. 2K-P). These findings indicate that FTO plays a promoting role in Mn-induced striatal injury.

\section{Effect of Mn exposure on nigro-striatal projection system}

To explore the role of Mn treatment on nigro-striatal projection system, FG labeling (Fig. 3A), the immunofluorescence triple staining of TH, DARPP32 and DAT (Fig. 3B), the DA levels (Fig. 3C) and neuronal axons growth (Fig. 3D-E) were determined to evaluate the survival rate of nigro-striatal neurons. In the control group, the boundary of neurons was clear and evident cell body were observed (Fig. 3A). In the $50 \mathrm{mg} / \mathrm{kg} \mathrm{MnCl}_{2}$ group, the boundary of neurons was unclear, the distribution of cells was uneven, the staining was lighter and disappeared significantly compared with the control group. (Fig. 3A). Reexpression of FTO significantly improved survival rate of nigro-striatal projection neurons compared with the $50 \mathrm{mg} / \mathrm{kg} \mathrm{MnCl} 2$ group (Fig. 3A). 
TH, DARPP32 and DAT are specific markers of nigro-striatal projection neurons, and their expression can reflect damage of nigro-striatal projection neurons. After treatment with $50 \mathrm{mg} / \mathrm{kg} \mathrm{MnCl}_{2}$, the nigrostriatal projection neurons marked with TH, DARPP32 and DAT were significantly reduced, and the projection system was severely damaged compared with the control group (Fig. 3B). Re-expression of FTO significantly restored the damage to the projection system compared with the $50 \mathrm{mg} / \mathrm{kg} \mathrm{MnCl}$ group (Fig. 3B). After treatment with $50 \mathrm{mg} / \mathrm{kg} \mathrm{MnCl}_{2}$, DA levels decreased significantly compared with control group (Fig. 3C). DA levels increased significantly after re-expression of FTO compared with the 50 $\mathrm{mg} / \mathrm{kg} \mathrm{MnCl} 2$ group. Neuronal axons grew slowly and shrank in the $50 \mathrm{mg} / \mathrm{kg} \mathrm{MnCl}_{2}$ group compared with control group (Fig. 3D and E). Neuronal axon length increased significantly after re-expression of FTO compared with the $50 \mathrm{mg} / \mathrm{kg} \mathrm{MnCl}_{2}$ group. On the contrary, the substantia-striatal projection system was significantly damaged after inhibition of FTO activity compared with that after over-expression of FTO (Fig. 3F-J).

\section{Role of FTO function in neuron and SH-SY5Y cells}

To explore the role of FTO in neuron and SH-SY5Y cells, the levels of FTO and total RNA $\mathrm{m}^{6} \mathrm{~A}$ and performed cytotoxicity were determined using neuron and SH-SY5Y cells (Fig. 4A-H). Over-expression of FTO (Fig. 4A-B, and Supplementary Fig. 4A) in Mn-induced FTO-low neuron and SH-SY5Y cells decreased the levels of total RNA $\mathrm{m}^{6} \mathrm{~A}$, and cytotoxicity (Fig. 4C-D). Inhibition of FTO activity in neurons and SHSY5Y cells significantly increased the levels of total RNA ${ }^{6} \mathrm{~A}$ and cytotoxicity (Fig. 4E-H). These findings indicate that FTO alleviates Mn-induced cytotoxicity in vitro.

\section{Role of $\mathrm{m}^{6} \mathrm{~A}$ in FTO functions in neuron and SH-SY5Y cells}

To explore the effect of $\mathrm{m}^{6} \mathrm{~A}$ in neuron and SH-SY5Y cells function, the gain-of-function of the $\mathrm{m}^{6} \mathrm{~A}$ writers METTL3/14 were determined (Fig. 5A-D, and Supplementary Fig. 4B-E). Forced over-expression of METTL3/14 significantly increased total $\mathrm{m}^{6} \mathrm{~A}$ levels (Fig. 5E, and Supplementary Fig. 4F) and decreased cell viability (Fig. 5F, and Supplementary Fig. 4G). Furthermore, over-expression of METTL3/14 inhibited effects of over-expression of FTO on the total $\mathrm{m}^{6} \mathrm{~A}$ levels and cell viability (Fig. $5 \mathrm{E}-\mathrm{F}$, and Supplementary Fig. 4F-G). These findings show that $\mathrm{m}^{6} \mathrm{~A}$ modification of mRNA increases toxicity and viability of $\mathrm{Mn}$ exposure on cells, indicating that $\mathrm{m}^{6} \mathrm{~A}$ exacerbates $\mathrm{Mn}$-induced parkinsonism.

\section{Identification of key target genes for FTO function}

Axon guiding molecules are expressed in the nigro-striatal projection system, whereas ephrins are mainly expressed in the striatum $[17,27]$. Inactivation of the FTO gene impairs DA receptors, controls activity and behavior of neurons in a dose-dependent manner. Therefore, analysis was performed to determine if ephrins are key targets of FTO after Mn exposure. Analysis showed showed that Mn exposure significantly reduces levels of ephrin-A4/5 and ephrin-B2 compared with the control group. Notably, levels of other ephrins of Mn exposed group showed no significant difference with those in the control group 
(Fig. 6A-B, and Supplementary Fig. 5A-D). Analysis showed that over-expression of FTO significantly increased ephrin-A5 and ephrin-B2 levels (Fig. 6C-H, and Supplementary Fig. 5E-F). In addition, overexpression of FTO significantly decreased mRNA $m^{6} A$ levels of ephrin-A5 and ephrin-B2, with no significant effect on expression of ephrin-A4 (Fig. 6I). On the other hand, downregulation of FTO activity significantly decreased ephrin-A5 and ephrin-B2 levels, and increased mRNA $\mathrm{m}^{6} \mathrm{~A}$ levels of ephrin-A5 and ephrin-B2 (Supplementary Fig. 5E-G). Notably, over-expression of FTO showed no effect on expression of other methylases (Supplementary Fig. 5H-K) implying that Mn affects expression of ephrins only by regulating FTO. These findings indicate that FTO inhibits expression of ephrin-A5 and ephrin-B2 after Mn exposure.

\section{Role of YTHDF2 on function of FTO in neurons}

$\mathrm{m}^{6} \mathrm{~A}$ regulates gene expression through YTH domain-containing family proteins [28]. In the present study, a gain function test was performed to explore mechanism of regulation of gene expression by $\mathrm{Mn}$ via determining $\mathrm{m}^{6} \mathrm{~A}$ RNA methylation (Fig. 7A) of YTHDF1/2. Over-expression of YTHDF1 showed no effect on the mRNA levels of ephrin-A5 and ephrin-B2 in the control group and FTO over-expression cells (Fig. 7B-E). However, over-expression of YTHDF2 significantly decreased levels of ephrin-B2 in both control and FTO over-expression cells, with no significant effect on expression of ephrin-A5 (Fig. 7F-I). In addition, over-expression of FTO significantly increased the stability of ephrin-B2 mRNA (Fig. 7J). Overexpression of YTHDF2 decreased the stability of ephrin-B2 mRNA (Fig. 7K). Immunofluorescence double staining of FTO and ephrin-B2 showed that Mn did not change the position of FTO and ephrin-B2. However, it decreased expression level of FTO and ephrin-B2. Notably, over-expression of FTO antagonized the effect of Mn (Fig. 7L). Grb4 and GIT1 are downstream target genes of ephrins, and play key roles in regulating axonal growth. The findings of the present study showed that $\mathrm{Mn}$ treatment decreased mRNA expression of Grb4 and GIT1 (Fig. 7M). Over-expression of FTO and activation of ephrin-B2 significantly increased expression of Grb4 and GIT1 (Fig. 7N-P). These findings show that YTHDF2 modulates expression of FTO target genes by mediating RNA decay.

\section{Role of FTO and ephrin-B2 in Mn-induced motor dysfunction}

The relationship between ephin-B2 and FTO-mediated motor dysfunction was explored. Forced activation of ephrin-B2 in FTO gene suppressor mice significantly increased performance of mice in rotating rod, fatigue meter, open field and gait tests (Fig. 8A-D and Supplementary Fig. 6A-I). Similarly, forced activation of ephrin-B2 in FTO suppressor mice significantly alleviated Mn-induced striatal morphological and functional damage (Fig. 8E-J). In addition, forced activation of ephrin-B2 in FTO suppressor neuronal cells significantly improved Mn-induced nigro-striatal projection system damage (Fig. 8K-0). These findings show that ephrin-B2 is a potential target of FTO in the striatum. In summary, the findings of the current study indicate that FTO plays a critical role in inhibiting effect of ephrin-B2 in Mn induced nigrostriatal projection system dysfunction, implying that activation of FTO can promote expression of ephrinB2 and then antagonize Mn-induced motor dysfunction. 


\section{Disscussion}

PD is a neurodegenerative disease characterized by bradykinesia. In the top 10 most populated countries in the world, the number of people with PD is projected to be between 8.7 and 9.3 million by 2030 [29]. Several studies report that PD is associated with disruptions in metallic ion homeostasis-mainly Mn [30, 31]. High levels of Mn results in parkinsonian-like symptoms known as manganism. This is mainly because neurodegeneration in PD occurs mainly in the DA neurons of the substantia nigra whereas Mn toxicity affects striatum. Both types of damage can decrease DA levels [30, 31]. Ephrins are important axon guidance molecules which play important roles in regulating motor function [32]. However, mechanisms of $\mathrm{Mn}$ in regulating motor function though axon guidance molecular ephrins has not been explored clearly.

Posttranscriptional regulation is implicated in axon guidance, and several RNA-binding proteins are involved in these mechanisms $[13,33]$. The findings of the current study show significant downregulation of FTO in Mn treated group in a dose-dependent manner. FTO inhibits striatal nerve and motor dysfunction caused by manganism in vivo. In addition, FTO inhibits toxicity of manganism cells in vitro. Notably, at the molecular level, FTO over-expression decreases total RNA $\mathrm{m}^{6} \mathrm{~A}$ level and upregulates key manganism inhibitory genes ephrin-A5 and ephrin-B2, and increases their mRNA stability. mRNA decay of ephrin-B2 gene in manganism cells is regulated by $\mathrm{m}^{6} \mathrm{~A}$ reader YTHDF2. On the contrary, pretreatment with FTO selective inhibitor MA2 aggravates Mn-induced neurological dysfunction. FTO is the RNA demethylase of $m^{6} A$ [34], which has the opposite effect on the stability of mRNA. The findings of this study showed that regulation of ephrin-B2 is partly regulated through the ${ }^{6} \mathrm{~A} / \mathrm{YTHDF} 2$ mechanism due to the following reasons: (1) FTO over-expression increased mRNA stability and level of ephrin-B2 gene, and decreased the abundance of $\mathrm{m}^{6} \mathrm{~A}$; (2) YTHDF2 and METTL3/14 over-expression decreased mRNA stability and level of ephrin-B2 gene, and reversed the effect of FTO over-expression. These findings imply that in Mn-induced parkinsonism, increase in $\mathrm{m}^{6} \mathrm{~A}$ level leads to RNA degradation of ephrin-B2 gene through a YTHDF2-dependent mechanism. However, several other undiscovered additional effects of FTO-regulated demethylation should be explored.

Mn neurotoxicity is correlated with impaired DA, glutamatergic and GABAergic transmission and neuroinflammation. Mn toxicity causes extrapyramidal motor dysfunction due to preferential accumulation of $\mathrm{Mn}$ in the striatum [35]. Previous studies report that ephrin signaling is important for normal connectivity and function of midbrain DA neurons [36, 37]. To verify that the observed defects resulted from the loss of FTO and ephrin-B2 mainly in the striatum, the role of ephrin-B2 activation in the striatum of mice in improving motor dysfunction was explored. The findings showed that increase in expression level of ephrin-B2 significantly improved their motor function. On the contrary, pretreatment with MA2 damaged motor function. These findings imply that deregulation of FTO and ephrin-B2 are significant mechanisms underlying Mn-induced neurotoxicity in mice. Future studies should be conducted to further explore anti-Mn effect of ephin-B2. 
Striatum is associated with several neurodegenerative diseases such as PD [38] and Huntington's Disease [39]. Effect of Mn linked on motor function in the striatum should be explored further. The findings of the current study show that Mn exposure causes pathological effects on the striatum characterized by cell loss, unusual shape and decrease in the number of neurons. These findings are consistent with previous findings by Song et al [40]. The findings of the current study showed that increase in ephrin-B2 significantly alleviates neuropathological damage and ultrastructural changes caused by manganism. Notably, the neuropathological injury was severe in the MA2 pretreatment groups. These findings show the effects of FTO and ephin-B2 on ultrastructural changes of Mn-induced neurotoxicity. Studies report that axon guide molecules perform an important role in regulating synaptic formation. Notably, axon guide molecules determine the location of synapses and regulate neuronal function [41-43]. In the current study, increased expression of ephrin-B2 antagonized Mn-induced dendritic spine density dysfunction. These findings show for the first time that ephin-B2 plays an important role in Mn-induced neuronal damage.

Brain DA neurons play important role in motor function control and related disorders by transmitting electrophysiological signals [44-47]. In addition, spontaneous firing activity is responsible for placing baseline DA ranges in the striatum [48], which regulate cognitive and motor function $[49,50]$. Therefore, determinants of the spontaneous firing activity in vivo play important roles in regulation of DA signaling and motor function. Notably, Mn-induced disappearance of spontaneous discharge was improved by ephrin-B2 activation. Spontaneous discharge frequency was damaged in MA2 pretreatment groups. These findings indicate a novel mechanism for Mn regulation of spontaneous firing rate of DA neurons in manganism.

Mn induced Parkinsonism is mainly caused by decrease in DA content in the striatum [12]. DA is derived from release of DA neurons from the substantia nigra after projecting to the striatum. This pathway is known as the nigro-striatal projection pathway of DA neurons [51]. To explore the effect of Mn exposure on snigro-striatal projection system, FG labeling, immunofluorescence triple staining of TH, DARPP32 and DAT, DA levels and neuronal axons growth were determined to evaluate the survival rate of nigro-striatal neurons. The findings showed that $\mathrm{Mn}$ treatment significantly damaged the nigro-striatal projection system, whereas re-expression of FTO and ephrin-B2 significantly increased survival rate of the projection neurons. Notably, substantia-striatal projection system was severely damaged after inhibition of FTO activity. These findings show that down-regulation of FTO and ephrin-B2 significantly affect morphology and function of the nigro-striatal projection system, implying that FTO mediated axon guidance promotes Mn-induced dysfunction of the nigro-striatal projection system, resulting in the failure of DA to be transmitted to the striatum, which may eventually cause striatal motor dysfunction.

\section{Conclusions}

In summary, the findings of the current study show that FTO over-expression inhibits Mn-induced parkinsonism and promotes expression of ephrin-B2 gene, partially through inhibits ephrin-B2 mRNA degradation, which is mediated by YTHDF2. In addition, promoting the expression of ephrin-B2 
antagonizes $\mathrm{Mn}$-induced parkinsonism in mice. These findings provide a basis to explore the specific mechanisms of Mn-induced motor dysfunction and provides a novel approach for treatment of Mninduced parkinsonism.

\section{Abbreviations}

AAV5: adeno-associated virus 5; ALKBH5:a-ketoglutarate-dependent dioxygenase alkB homolog 5; CCK8:Cell Counting Kit-8; CNS:central nervous system; DA:dopamine; DAPI:2-(4-Amidinophenyl)-6indolecarbamidine dihydrochloride; DARPP32:Dopamine- and cAMP-regulated neuronal phosphoprotein $32 \mathrm{kDa}$; DAT:dopamine transporter; DMEM:Dulbecco's modified Eagle's medium; ELISA:Enzyme-linked immunosorbent assay; ephrins:erythropoietin-producing hepatocyte receptor-interacting proteins; FBS:fetal bovine serum; FG:Fluoro-Gold; FTO:fat mass and obesity-associated protein; HE:Hematoxylin and eosin; HRP:Horseradish peroxidase; ICP-MS:inductively coupled plasma mass spectrometry; i.p:intraperitoneal; $\mathrm{m}^{6} \mathrm{~A}: \mathrm{N}^{6}$-methyladenosine; MA2:Ethyl ester derivative of MA; $\mathrm{mACSF}$ :modified artificial cerebrospinal fluid; METTL3:methyltransferase like 3; $\mathrm{MnCl}_{2}$ :Manganese chloride; $\mathrm{Mn}$ :Manganese; NC:negative control; OE:over-expression; PBS:phosphate buffered solution; PD:Parkinson's disease; PVDF:polyvinylidene difluoride; RT-qPCR:Real-time quantitative PCR; s.c:subcutaneous; TH:tyrosine hydroxylase; YTHDF1/2:YT521-B homology domain family proteins $1 / 2$

\section{Declarations}

\section{Availability of data and material}

All data generated or analyzed during this study are included in this published article.

\section{Funding}

We gratefully acknowledge funding from the Natural Science Foundation of Liaoning Province [2020-MS152], the Basic Research Fund of Young Program of Higher Education of Liaoning Province (Grant No. QNK201735), and the Funds for Distinguished Young Scientists in School of Public Health, China Medical University.

\section{Authors' contributions}

Each author notably contributed to the article. Zhipeng Qi: design and draft the article; Jiashuo Li, Ke Zhang, Yanan, Liu, Xinxin Yang, Minghui Li, Xianchao Du, Lei Zhang, Yi Wen, Bin Xu, Wei Liu, and Zhaofa $\mathrm{Xu}$ : revise the manuscript; Yu Deng: conception, design, and revise it severely for essential intellectual content, and final approval of the version to be published. All authors read and permitted the final version of the manuscript.

\section{Acknowledgements}


We would like to acknowledge Hui Yuan, Fengdi Wu, Haiying Wang, Bingchen Liu, Shuang Wang, Xuda Liu, Rong Cui, Binbin Liu, Tingwei Pan and Miaoling Wu for their valuable advices.

\section{Competing interests}

The authors declare that they have no competing interests.

\section{Author details}

${ }^{1}$ Department of Environmental Health, School of Public Health, China Medical University, Puhe Road, ShenBei New Area, Shenyang, Liaoning 110122, People's Republic of China. ${ }^{2}$ Department of Developmental Cell Biology, Key Laboratory of Cell Biology, Ministry of Public Health, Key Laboratory of Medical Cell Biology, Ministry of Education, China Medical University, Puhe Road, ShenBei New Area, Shenyang, Liaoning 110122, People's Republic of China. ${ }^{3}$ Department of Preventive Health, Zhuhai People's Hospital, Kangning Road, Xiangzhou Area, Zhuhai, Guangdong, 519070, People's Republic of China.

\section{References}

1. Kalia LV, Lang AE. Parkinson's disease. Lancet. 2015;386(9996):896-912.

2. Li G, Ma J, Cui S, He Y, Xiao Q, Liu J, et al. Parkinson's disease in China: a forty-year growing track of bedside work. Transl Neurodegener. 2019;8:22.

3. Lauretti E, Di Meco A, Merali S, Pratico D. Circadian rhythm dysfunction: a novel environmental risk factor for Parkinson's disease. Mol Psychiatry. 2017;22(2):280-6.

4. Gorell JM, Johnson CC, Rybicki BA, Peterson EL, Kortsha GX, Brown GG, et al. Occupational exposure to manganese, copper, lead, iron, mercury and zinc and the risk of Parkinson's disease. Neurotoxicology. 1999;20(2-3):239-47.

5. Horning KJ, Caito SW, Tipps KG, Bowman AB, Aschner M. Manganese Is Essential for Neuronal Health. Annu Rev Nutr. 2015;35:71-108.

6. Guilarte TR. Manganese and Parkinson's disease: a critical review and new findings. Environ Health Perspect. 2010;118(8):1071-80.

7. Vijayan B, Raj V, Nandakumar S, Kishore A, Thekkuveettil A. Spermine protects alpha-synuclein expressing dopaminergic neurons from manganese-induced degeneration. Cell Biol Toxicol. 2019;35(2):147-59.

8. Racette BA, Searles NS, Criswell SR, Sheppard L, Seixas N, Warden MN, et al. Dose-dependent progression of parkinsonism in manganese-exposed welders. Neurology. 2017;88(4):344-51.

9. Pajarillo E, Johnson JJ, Kim J, Karki P, Son DS, Aschner M, et al. 17beta-estradiol and tamoxifen protect mice from manganese-induced dopaminergic neurotoxicity. Neurotoxicology. 2018;65:280-8.

10. Yang X, Yang H, Wu F, Qi Z, Li J, Xu B, et al. Mn Inhibits GSH Synthesis via Downregulation of Neuronal EAAC1 and Astrocytic XCT to Cause Oxidative Damage in the Striatum of Mice. Oxid Med 
Cell Longev. 2018;2018:4235695.

11. Criswell SR, Warden MN, Searles NS, Perlmutter JS, Moerlein SM, Sheppard L, et al. Selective D2 receptor PET in manganese-exposed workers. Neurology. 2018;91(11):e1022-30.

12. Peneder TM, Scholze P, Berger ML, Reither H, Heinze G, Bertl J, et al. Chronic exposure to manganese decreases striatal dopamine turnover in human alpha-synuclein transgenic mice. Neuroscience. 2011;180:280-92.

13. Zhuang M, Li X, Zhu J, Zhang J, Niu F, Liang F, et al. The m6A reader YTHDF1 regulates axon guidance through translational control of Robo3.1 expression. Nucleic Acids Res. 2019;47(9):476577.

14. Soleilhavoup C, Travaglio M, Patrick K, Garcao P, Boobalan E, Adolfs Y, et al. Nolz1 expression is required in dopaminergic axon guidance and striatal innervation. Nat Commun. 2020;11(1):3111.

15. Livesey FJ, Hunt SP. Netrin and netrin receptor expression in the embryonic mammalian nervous system suggests roles in retinal, striatal, nigral, and cerebellar development. Mol Cell Neurosci. 1997;8(6):417-29.

16. Seiradake E, Jones EY, Klein R. Structural Perspectives on Axon Guidance. Annu Rev Cell Dev Biol. 2016;32:577-608.

17. Brambilla R, Bruckner K, Orioli D, Bergemann AD, Flanagan JG, Klein R. Similarities and differences in the way transmembrane-type ligands interact with the Elk subclass of Eph receptors. Mol Cell Neurosci. 1996;8(2-3):199-209.

18. Sieber BA, Kuzmin A, Canals JM, Danielsson A, Paratcha G, Arenas E, et al. Disruption of EphA/ephrin-a signaling in the nigrostriatal system reduces dopaminergic innervation and dissociates behavioral responses to amphetamine and cocaine. Mol Cell Neurosci. 2004;26(3):41828.

19. Liu J, Harada BT, He C. Regulation of Gene Expression by N(6)-methyladenosine in Cancer. Trends Cell Biol. 2019;29(6):487-99.

20. Yu J, Chen M, Huang H, Zhu J, Song H, Zhu J, et al. Dynamic m6A modification regulates local translation of mRNA in axons. Nucleic Acids Res. 2018;46(3):1412-23.

21. Yue Y, Liu J, He C. RNA N6-methyladenosine methylation in post-transcriptional gene expression regulation. Genes Dev. 2015;29(13):1343-55.

22. Jia G, Fu Y, Zhao X, Dai Q, Zheng G, Yang Y, et al. N6-methyladenosine in nuclear RNA is a major substrate of the obesity-associated FTO. Nat Chem Biol. 2011;7(12):885-7.

23. Zhang L, Cheng Y, Xue Z, Li J, Wu N, Yan J, et al. Sevoflurane impairs m6A-mediated mRNA translation and leads to fine motor and cognitive deficits. Cell Biol Toxicol. 2021.

24. Weng YL, Wang X, An R, Cassin J, Vissers C, Liu Y, et al. Epitranscriptomic m(6)A Regulation of Axon Regeneration in the Adult Mammalian Nervous System. Neuron. 2018;97(2):313-25.e6.

25. Richard EM, Polla DL, Assir MZ, Contreras M, Shahzad M, Khan AA, et al. Bi-allelic Variants in METTL5 Cause Autosomal-Recessive Intellectual Disability and Microcephaly. Am J Hum Genet. 
2019;105(4):869-78.

26. Hess ME, Hess S, Meyer KD, Verhagen LA, Koch L, Bronneke HS, et al. The fat mass and obesity associated gene (Fto) regulates activity of the dopaminergic midbrain circuitry. Nat Neurosci. 2013;16(8):1042-8.

27. Soleilhavoup C, Travaglio M, Patrick K, Garcao P, Boobalan E, Adolfs Y, et al. Nolz1 expression is required in dopaminergic axon guidance and striatal innervation. Nat Commun. 2020;11(1):3111.

28. Dominissini D, Moshitch-Moshkovitz S, Schwartz S, Salmon-Divon M, Ungar L, Osenberg S, et al. Topology of the human and mouse m6A RNA methylomes revealed by m6A-sEq. Nature. 2012;485(7397):201-6.

29. Dorsey ER, Constantinescu R, Thompson JP, Biglan KM, Holloway RG, Kieburtz K, et al. Projected number of people with Parkinson disease in the most populous nations, 2005 through 2030. Neurology. 2007;68(5):384-6.

30. Sun Y, He Y, Yang L, Liang D, Shi W, Zhu X, et al. Manganese induced nervous injury by alphasynuclein accumulation via ATP-sensitive $\mathrm{K}(+)$ channels and GABA receptors. Toxicol Lett. 2020;332:164-70.

31. Lu X, Kim-Han JS, Harmon S, Sakiyama-Elbert SE, O'Malley KL. The Parkinsonian mimetic, 6-OHDA, impairs axonal transport in dopaminergic axons. Mol Neurodegener. 2014;9:17.

32. Lahaie S, Morales D, Bagci H, Hamoud N, Castonguay CE, Kazan JM, et al. The endosomal sorting adaptor HD-PTP is required for ephrin-B:EphB signalling in cellular collapse and spinal motor axon guidance. Sci Rep. 2019;9(1):11945.

33. Preitner N, Quan J, Li X, Nielsen FC, Flanagan JG. IMP2 axonal localization, RNA interactome, and function in the development of axon trajectories. Development. 2016;143(15):2753-9.

34. Niu Y, Lin Z, Wan A, Chen H, Liang H, Sun L, et al. RNA N6-methyladenosine demethylase FTO promotes breast tumor progression through inhibiting BNIP3. Mol Cancer. 2019;18(1):46.

35. Deng Y, Jiao C, Mi C, Xu B, Li Y, Wang F, et al. Melatonin inhibits manganese-induced motor dysfunction and neuronal loss in mice: involvement of oxidative stress and dopaminergic neurodegeneration. Mol Neurobiol. 2015;51(1):68-88.

36. Sun JH, Gao Q, Zhang J, Bao LH, Dong HM, Liang N, et al. Ephrinb3 induces mesostriatal dopaminergic projection to the striatum. Biochem Biophys Res Commun. 2010;400(2):194-9.

37. Wang T, Chen J, Tang CX, Zhou XY, Gao DS. Inverse Expression Levels of EphrinA3 and EphrinA5 Contribute to Dopaminergic Differentiation of Human SH-SY5Y Cells. J Mol Neurosci. 2016;59(4):483-92.

38. Ketzef M, Spigolon G, Johansson Y, Bonito-Oliva A, Fisone G, Silberberg G. Dopamine Depletion Impairs Bilateral Sensory Processing in the Striatum in a Pathway-Dependent Manner. Neuron. 2017;94(4):855-65.e5.

39. Cherubini M, Lopez-Molina L, Gines S. Mitochondrial fission in Huntington's disease mouse striatum disrupts ER-mitochondria contacts leading to disturbances in $\mathrm{Ca}(2+)$ efflux and Reactive Oxygen Species (ROS) homeostasis. Neurobiol Dis. 2020;136:104741. 
40. Song Q, Deng Y, Yang X, Bai Y, Xu B, Liu W, et al. Manganese-Disrupted Interaction of Dopamine D1 and NMDAR in the Striatum to Injury Learning and Memory Ability of Mice. Mol Neurobiol. 2016;53(10):6745-58.

41. Frei JA, Stoeckli ET. SynCAMs - From axon guidance to neurodevelopmental disorders. Mol Cell Neurosci. 2017;81:41-8.

42. Varshney A, Benedetti K, Watters K, Shankar R, Tatarakis D, Coto VD, et al. The receptor protein tyrosine phosphatase CLR-1 is required for synaptic partner recognition. Plos Genet. 2018;14(5):e1007312.

43. Stanic K, Saldivia N, Forstera B, Torrejon M, Montecinos H, Caprile T. Expression Patterns of Extracellular Matrix Proteins during Posterior Commissure Development. Front Neuroanat. 2016;10:89.

44. Kriks S, Shim JW, Piao J, Ganat YM, Wakeman DR, Xie Z, et al. Dopamine neurons derived from human ES cells efficiently engraft in animal models of Parkinson's disease. Nature. 2011;480(7378):547-51.

45. Branch SY, Chen C, Sharma R, Lechleiter JD, Li S, Beckstead MJ. Dopaminergic Neurons Exhibit an Age-Dependent Decline in Electrophysiological Parameters in the MitoPark Mouse Model of Parkinson's Disease. J Neurosci. 2016;36(14):4026-37.

46. Stamatakis AM, Jennings JH, Ung RL, Blair GA, Weinberg RJ, Neve RL, et al. A unique population of ventral tegmental area neurons inhibits the lateral habenula to promote reward. Neuron. 2013;80(4):1039-53.

47. Picconi B, De Leonibus E, Calabresi P. Synaptic plasticity and levodopa-induced dyskinesia: electrophysiological and structural abnormalities. J Neural Transm (Vienna). 2018;125(8):1263-71.

48. Meza RC, Lopez-Jury L, Canavier CC, Henny P. Role of the Axon Initial Segment in the Control of Spontaneous Frequency of Nigral Dopaminergic Neurons In Vivo. J Neurosci. 2018;38(3):733-44.

49. Engelhard B, Finkelstein J, Cox J, Fleming W, Jang HJ, Ornelas S, et al. Specialized coding of sensory, motor and cognitive variables in VTA dopamine neurons. Nature. 2019;570(7762):509-13.

50. Mckinley JW, Shi Z, Kawikova I, Hur M, Bamford IJ, Sudarsana DS, et al. Dopamine Deficiency Reduces Striatal Cholinergic Interneuron Function in Models of Parkinson's Disease. Neuron. 2019;103(6):1056-72.e6.

51. Koutzoumis DN, Vergara M, Pino J, Buddendorff J, Khoshbouei H, Mandel RJ, et al. Alterations of the gut microbiota with antibiotics protects dopamine neuron loss and improve motor deficits in a pharmacological rodent model of Parkinson's disease. Exp Neurol. 2020;325:113159.

\section{Figures}


A

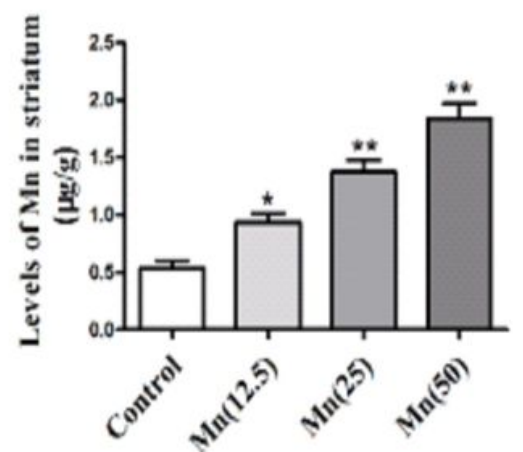

D
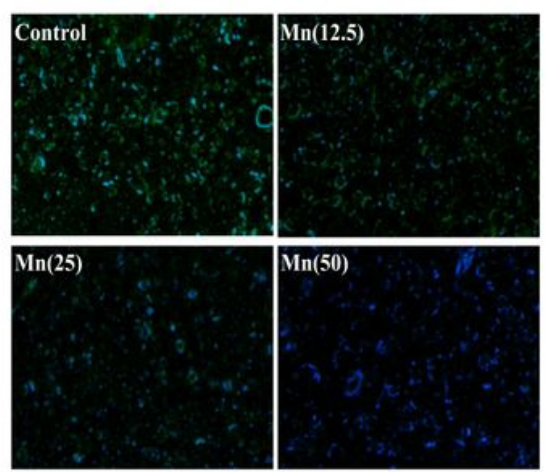

G

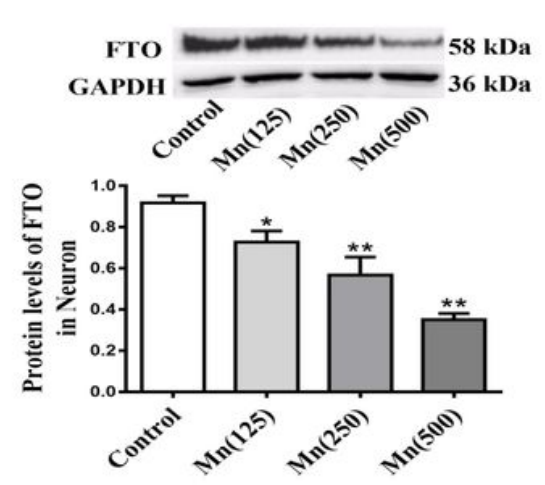

B

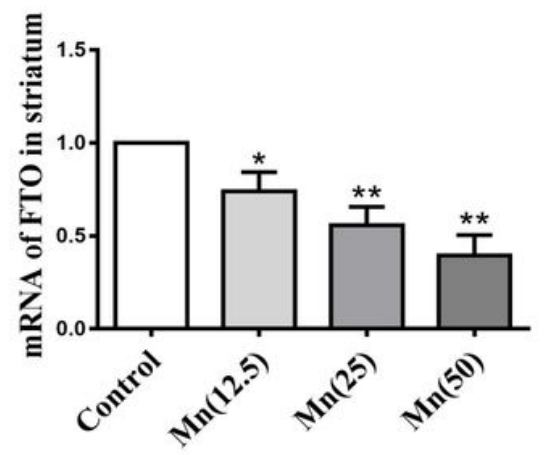

E

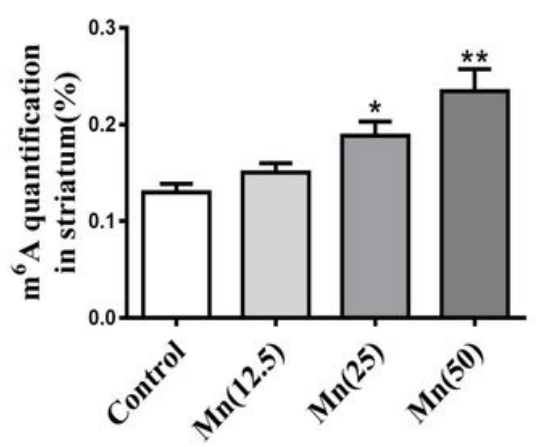

H

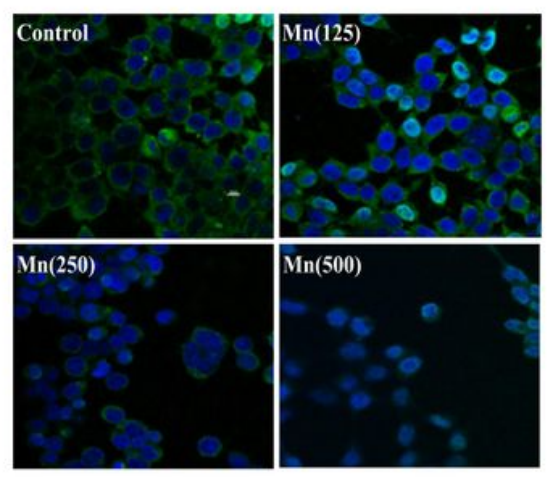

C

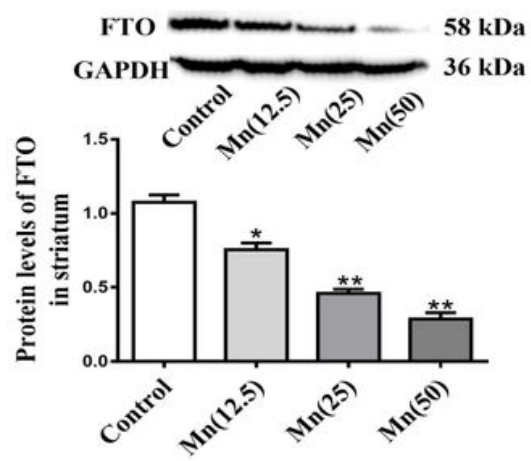

F

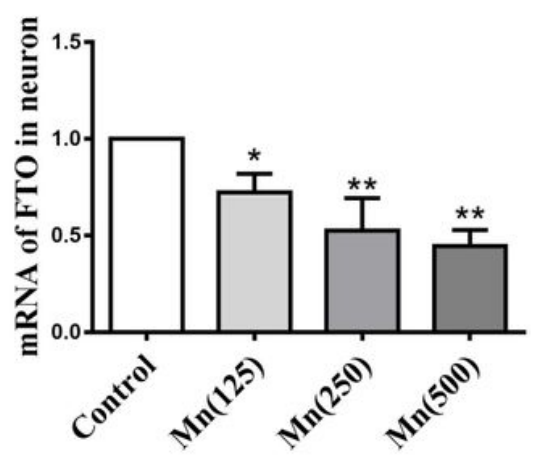

I

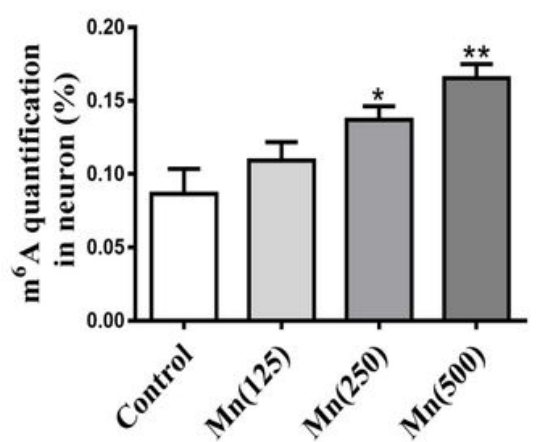

Figure 1

FTO is upregulated in striatum after $\mathrm{Mn}$ exposure. A Mn levels in striatum. B, F mRNA expression level of FTO in striatum and neurons. C, G FTO protein levels in striatum and neurons. D, H Immunofluorescence staining of FTO in striatum and neurons. Nuclei are counterstained with DAPI in blue, FTO are counterstained in green. Scale bar, $100 \mu \mathrm{m}$. E, I Total RNA m6A levels in striatum and neurons. Data are expressed as mean \pm S.D. $(n \geq 3) .{ }^{*}<<0.05,{ }^{*} P<0.01$ indicates statistical significance compared with control group. 
A

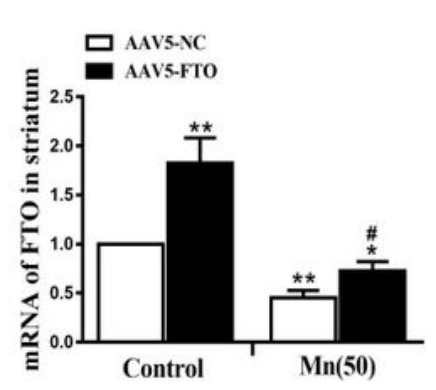

E

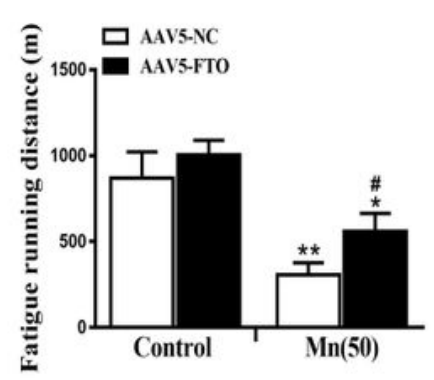

I

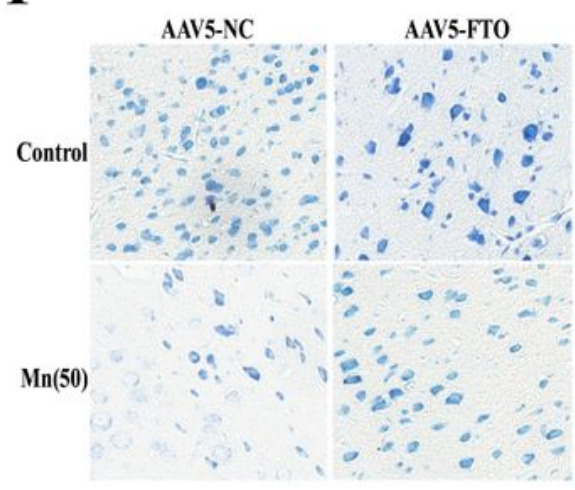

L

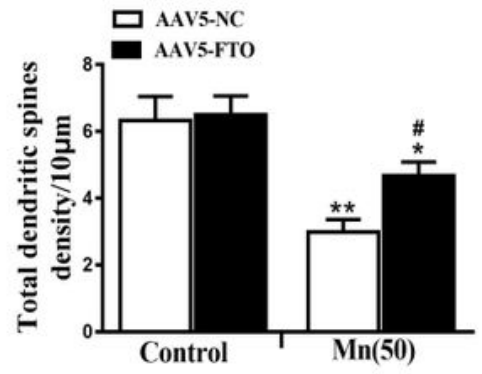

B

F
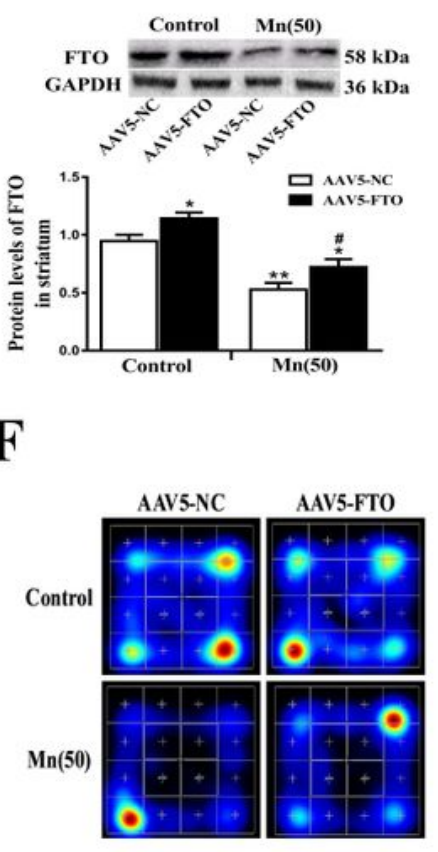

J

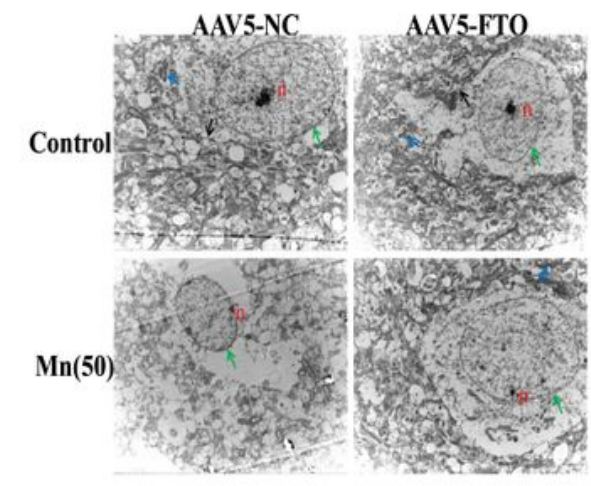

M

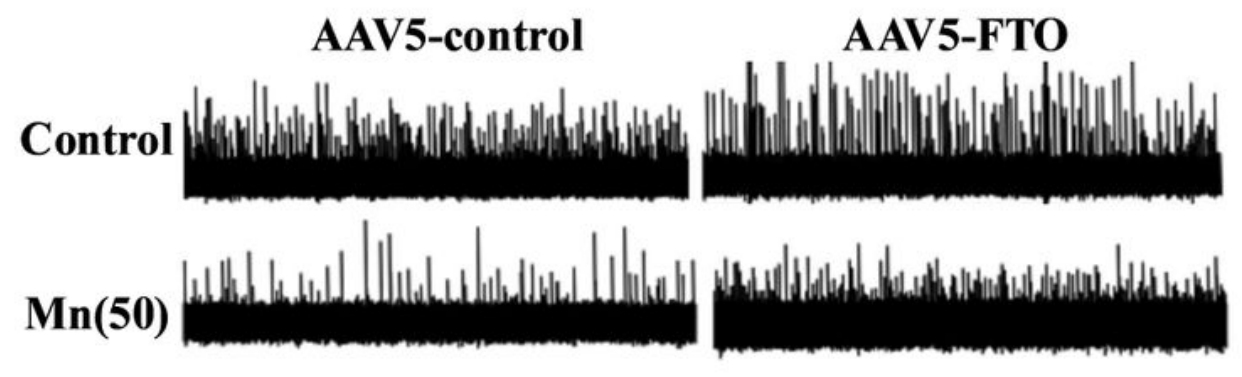

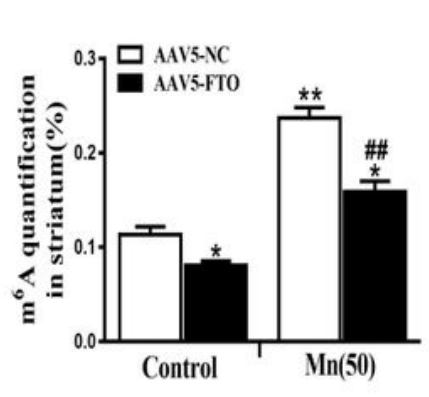

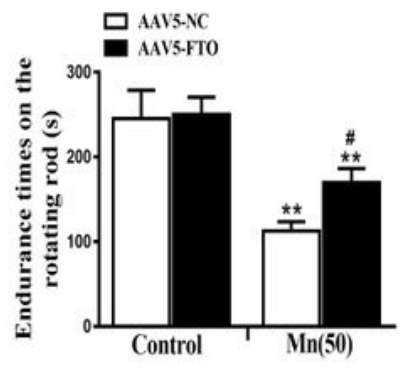

G

\section{H}

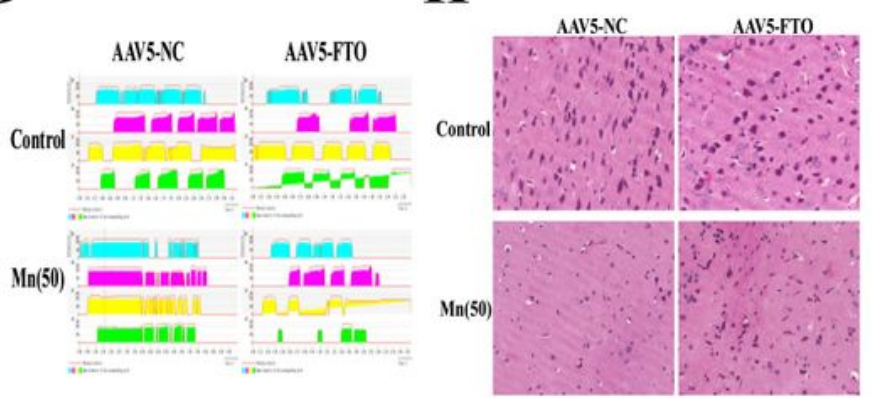

K

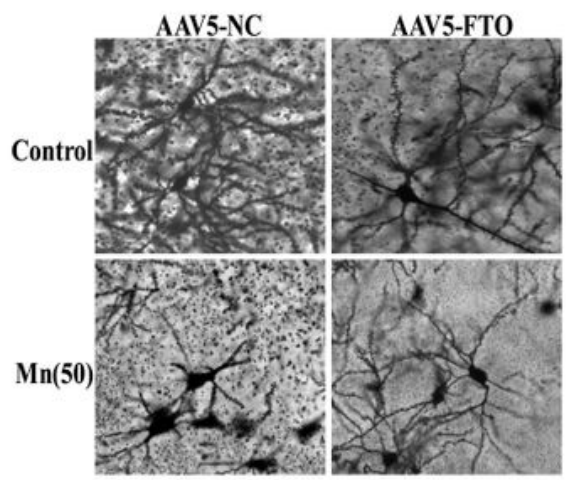

\section{Figure 2}

Selective FTO re-expression or inhibition of FTO activity in the striatum rescues defects in motor function and morphological changes after Mn exposure. A mRNA expression level of FTO in striatum. B FTO protein levels in striatum. C Total RNA m6A levels in striatum. D Endurance times on the rotating rod. E Fatigue running distance in the fatigue meter. F Heat map of activity in the open field. G Mean intensity in the gait tests. H HE staining of striatum after Mn exposure and/or intervention by FTO expression. I Nissl 
staining of striatum after Mn treatment and/or intervention by FTO expression. J Electron microphotograph of striatum after Mn treatment and/or intervention by FTO expression. Green arrowheads represent the nuclear membrane, $\mathrm{n}$ representative nuclei, blue arrow-heads represent mitochondria, black arrows represent endoplasmic reticulum. K-L Golgi-Cox staining of striatum after Mn exposure and/or intervention by FTO expression. M Trace representative spontaneous firing recorded by MED64 after $\mathrm{Mn}$ exposure and/or intervention by FTO expression. Magnification of the sections stained with HE, Nissl, and Golgi-Cox was $\times 400$. Magnification of the electron microphotograph was $\times 4,000$. Data are expressed as mean \pm S.D. $(n \geq 3)$. ${ }^{*}<<0.05,{ }^{*} P<0.01$ indicates statistical significance compared with the control (AAV5-NC) group; \#P<0.05 indicates statistical significance compared with the $50 \mathrm{mg} / \mathrm{kg} \mathrm{MnCl} 2$ (AAV5-NC) group.

A

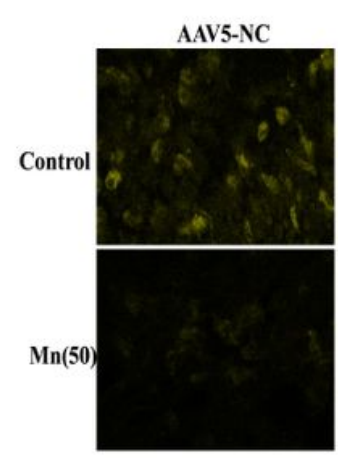

D

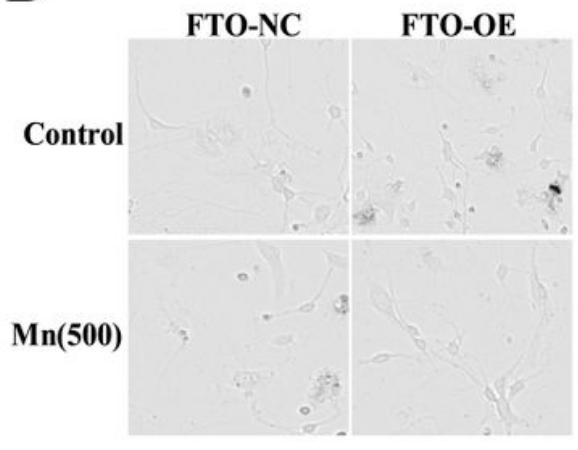

G

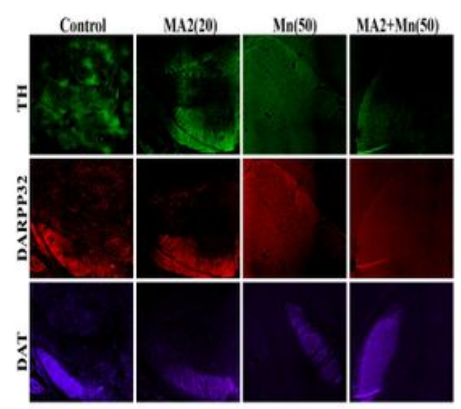

B

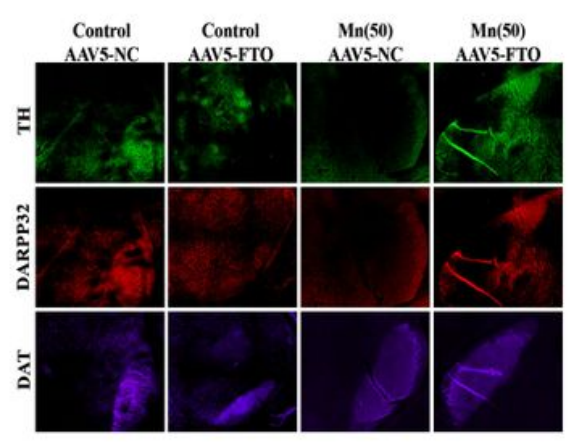

E

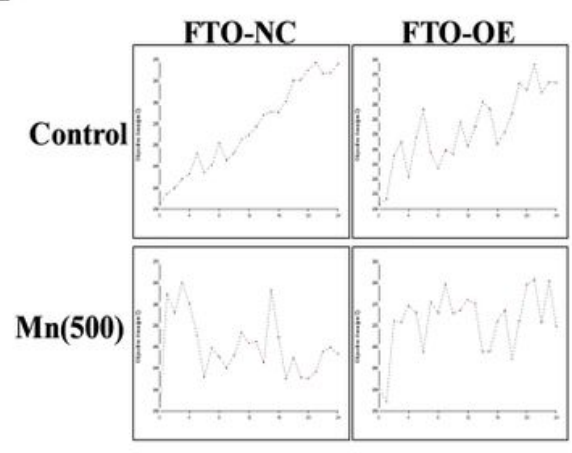

I
C

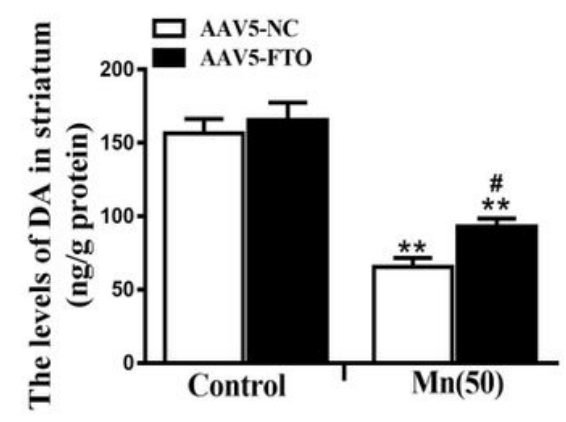

F
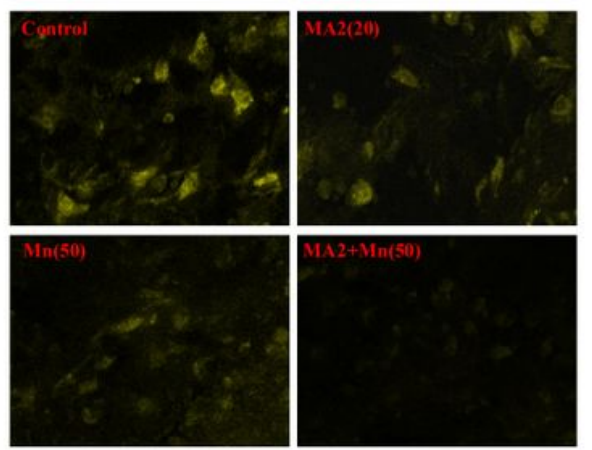

J
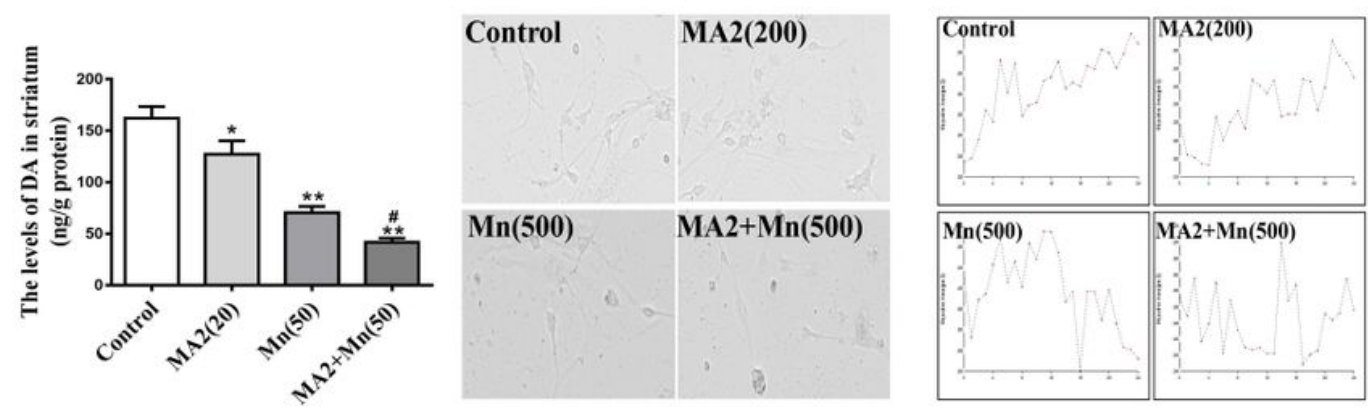

Figure 3 
Effect of Mn exposure on nigro-striatal projection system. A, F Retrograde labeling of nigro-striatal projection neurons with FG after Mn exposure and/or intervention by FTO expression. B, G Immunofluorescence triple staining of TH, DARPP32 and DAT. TH are counterstained in green, DARPP32 are counterstained in red, and DAT are counterstained in purple. C, H DA levels of striatum after Mn exposure and/or intervention by FTO expression. D-E, I-J Changes in neuronal axons growth with live cell station after $\mathrm{Mn}$ exposure and/or intervention by FTO expression. Magnification of sections stained with FG was $\times 400$. Data are expressed as mean \pm S.D. $(n \geq 3) .{ }^{*} P<0.05, * \star P<0.01$ indicates statistical significance compared with the control (with or without AAV5-NC) group; $\# \mathrm{P}<0.05$ indicates statistical significance compared with the $50 \mathrm{mg} / \mathrm{kg} \mathrm{MnCl} 2$ (with or without AAV5-NC) group. 

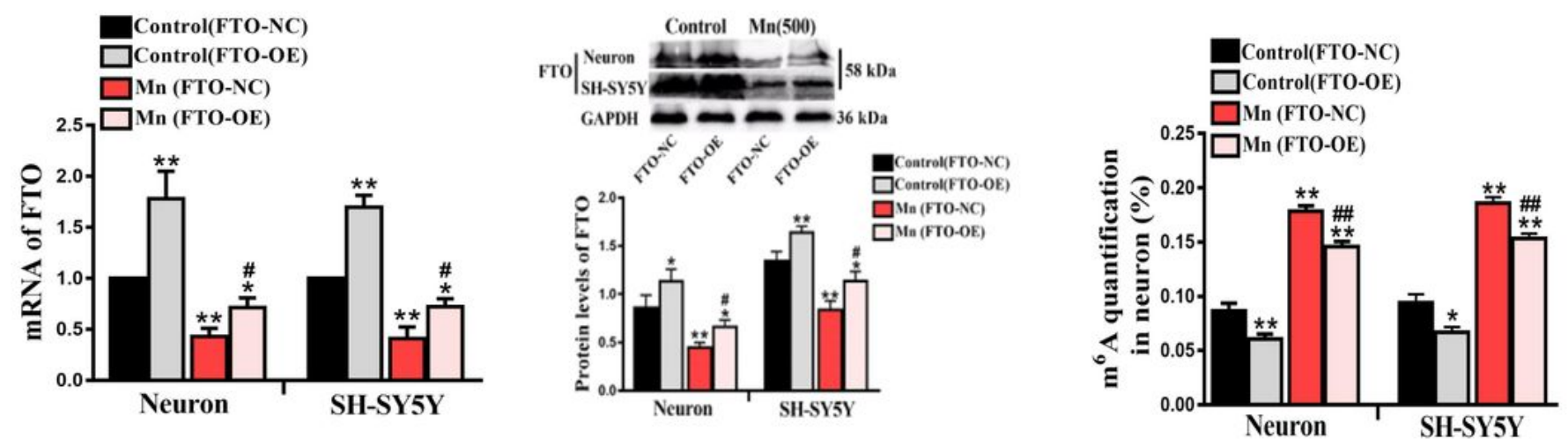

D

$\mathbf{E}$

$\mathbf{F}$
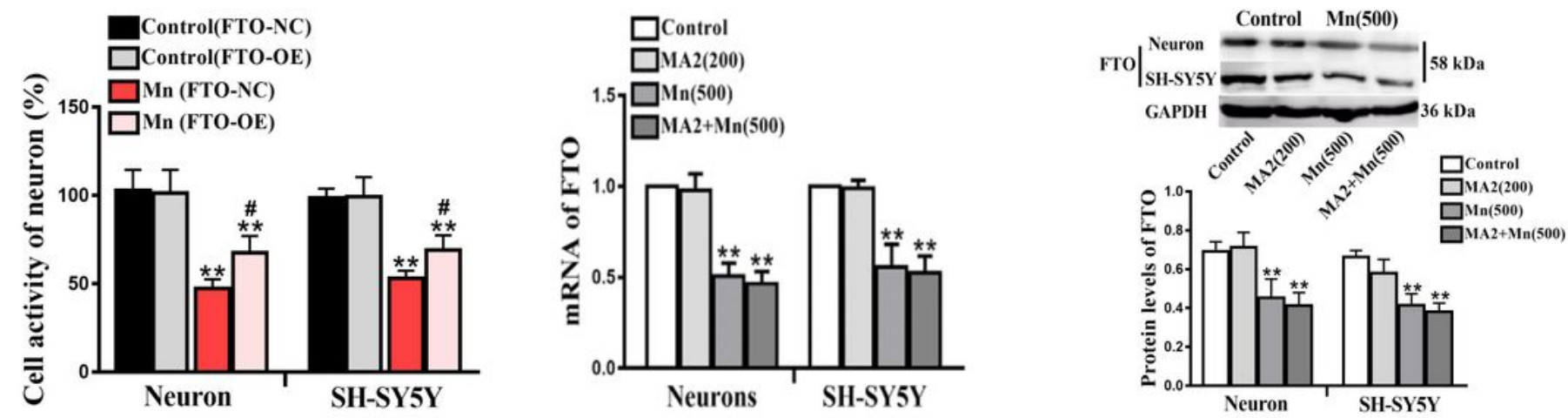

G

$\mathbf{H}$
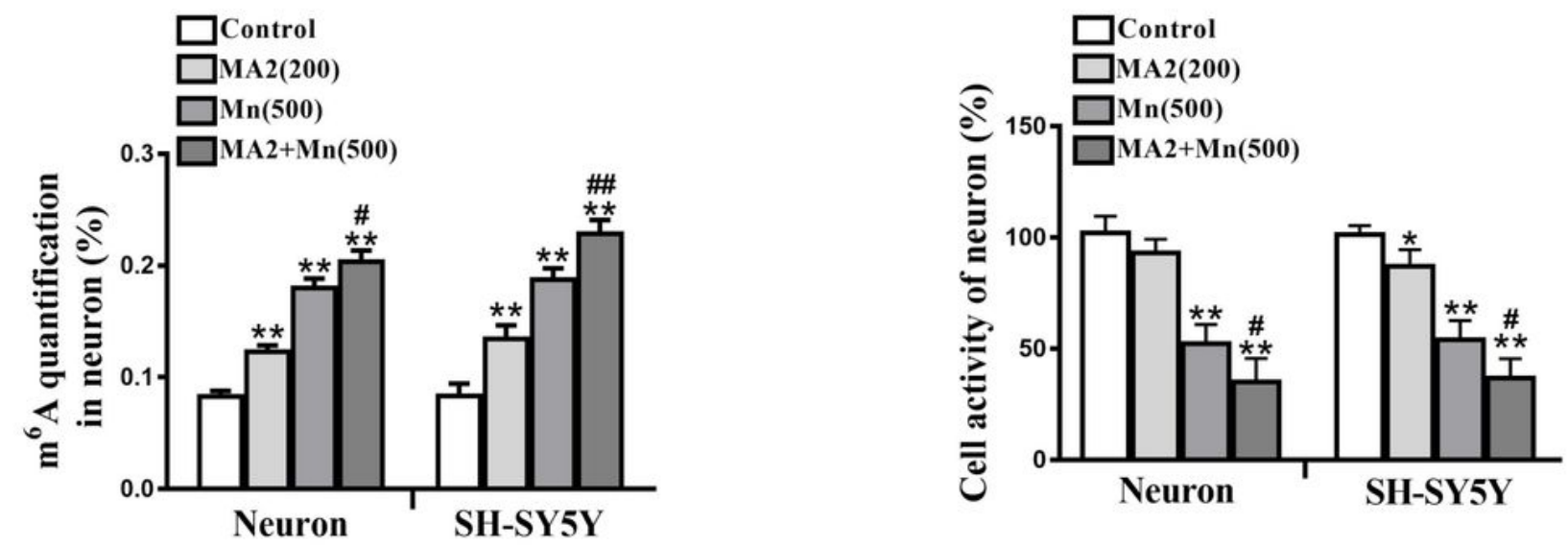

Figure 4

Effect of FTO re-expression or inhibition of FTO activity in neurons and SH-SY5Y cells. A-B, E-F Expression levels of FTO in neuron and SH-SY5Y cells by real time PCR and immunoblot analysis after over-expression or inhibition. C, G Total RNA m6A levels in neuron and SH-SY5Y with FTO-NC, FTO-OE (FTO over-expression), or MA2 (inhibition of FTO activity). D, H Cell viability assay in neuron and SH-SY5Y cells with FTO-NC, FTO-OE (FTO over-expression), or MA2 (inhibition of FTO activity). Data are expressed 
as mean \pm S.D. $(n \geq 3) .{ }^{*} P<0.05,{ }^{*} \times P<0.01$ indicates statistical significance compared with the control (with or without FTO-NC) group; \#P<0.05, \#\#P<0.01 indicates statistical significance compared with the $50 \mathrm{mg} / \mathrm{kg} \mathrm{MnCl} 2$ (with or without FTO-NC) group.
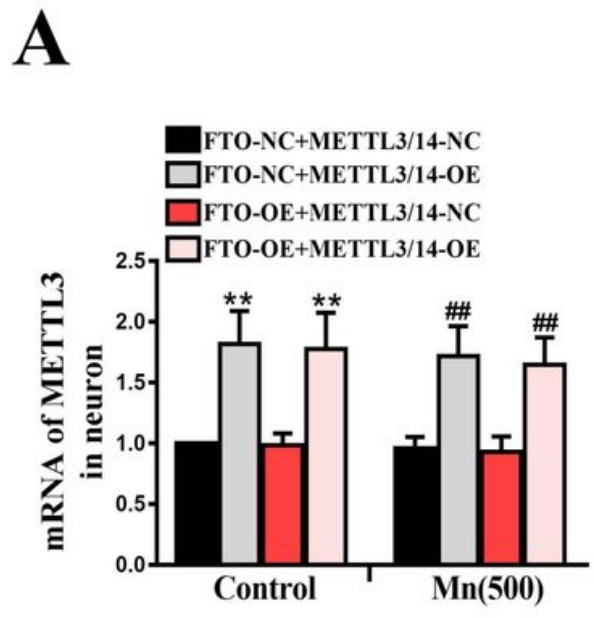

D

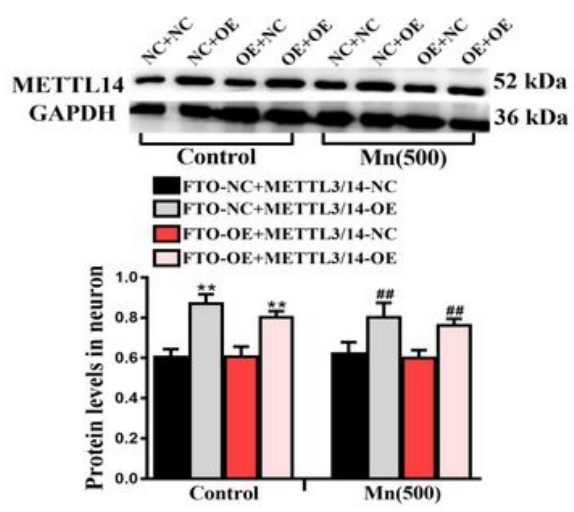

B

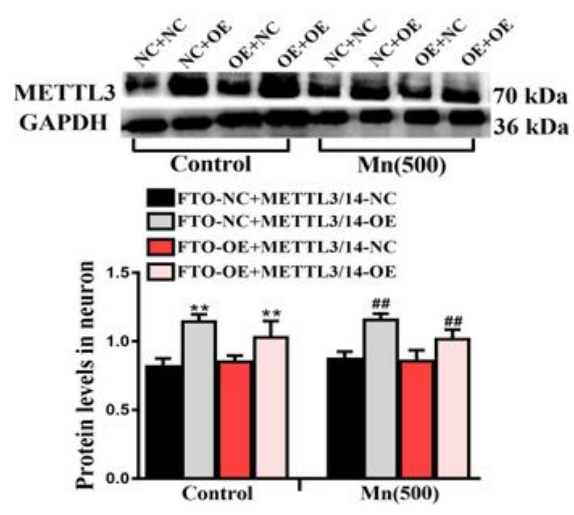

$\mathbf{E}$

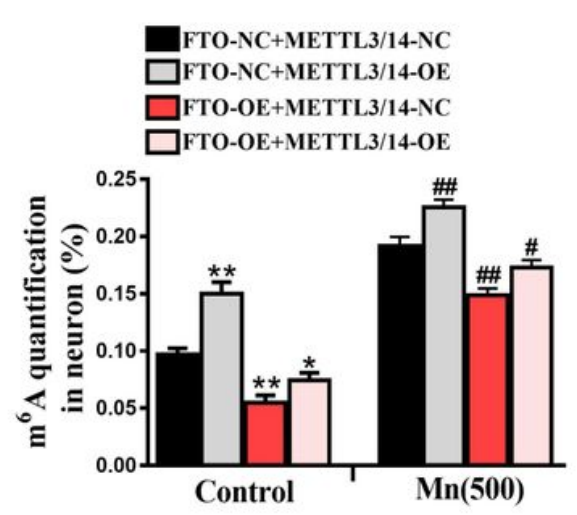

\section{C}

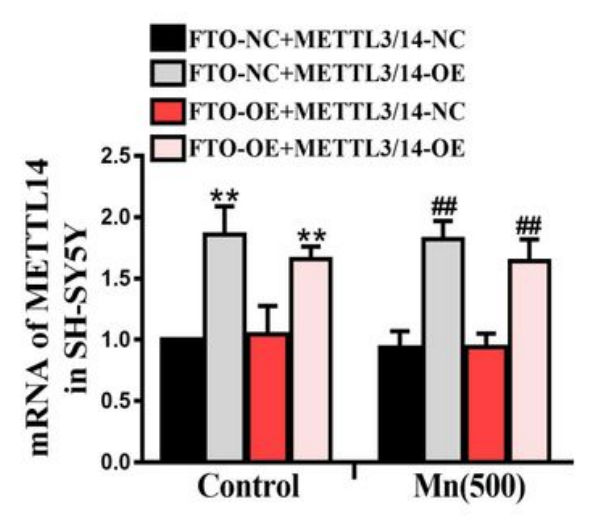

F

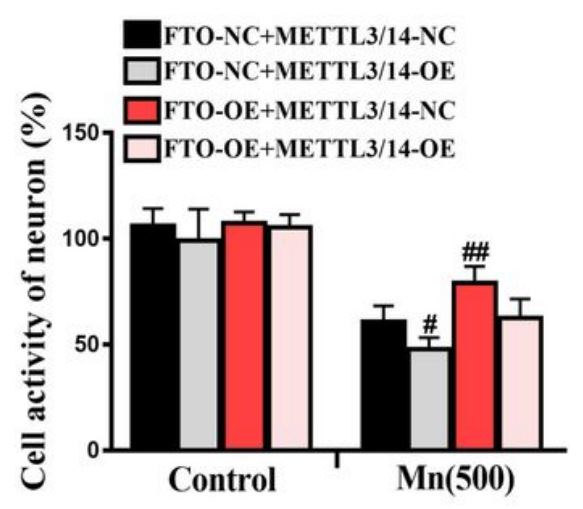

Figure 5

Function of m6A in neuron cells. A-D Expression levels of METTL3/14 or FTO neuron cells by real time PCR and immunoblot analysis after over-expression. E Total RNA m6A levels in neuron cells. F Cell viability assay using neuron cells. Data are expressed as mean \pm S.D. $(n \geq 3) .{ }^{*}<0.05, * * P<0.01$ indicates statistical significance compared with the control (FTO-NC+METTL3/14-NC) group; \#P<0.05, \#\#P<0.01 indicates statistical significance compared with the $50 \mathrm{mg} / \mathrm{kg} \mathrm{MnCl} 2$ (FTO-NC+METTL3/14-NC) group. 
B
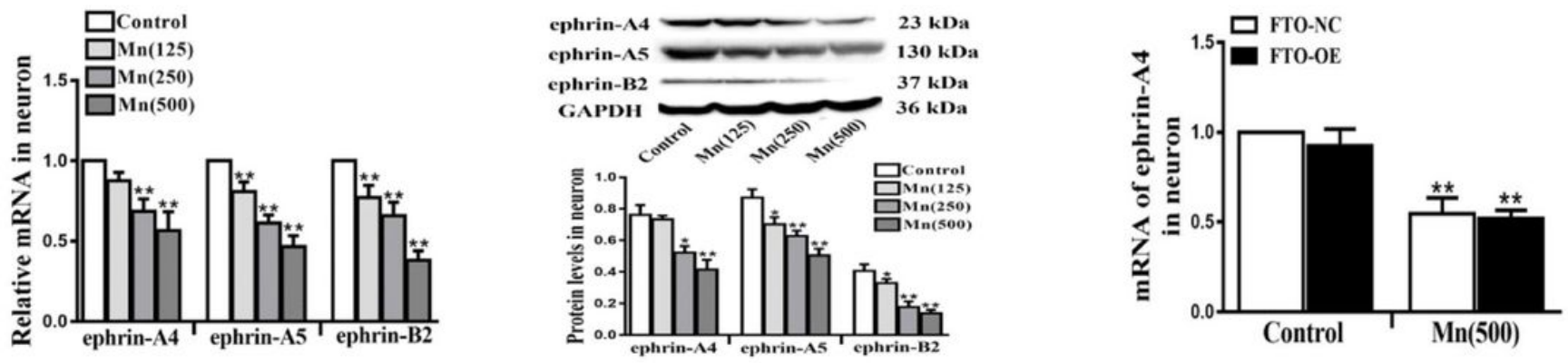

$\mathrm{D}$

$\mathrm{E}$
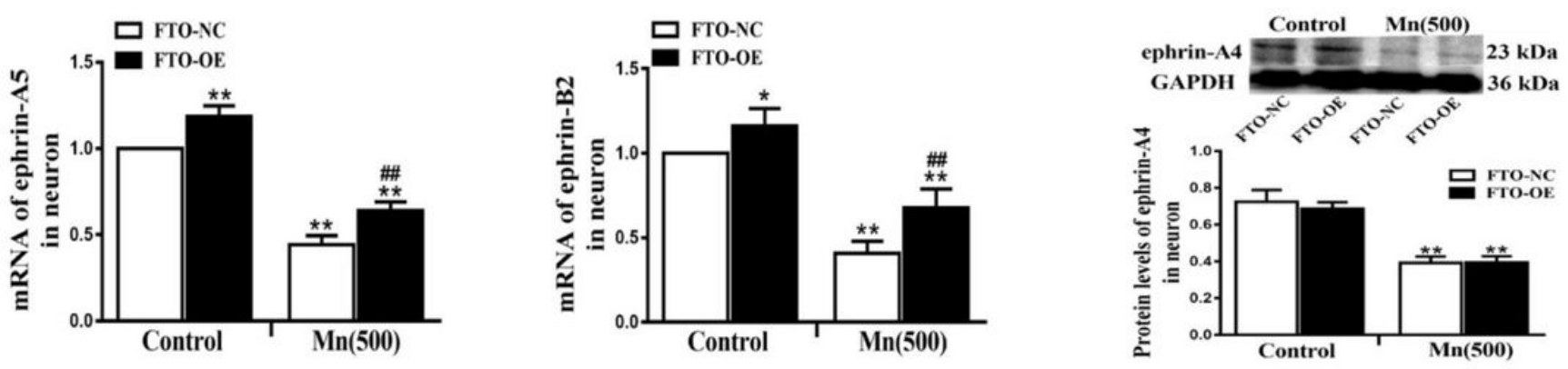

G

$\mathrm{H}$
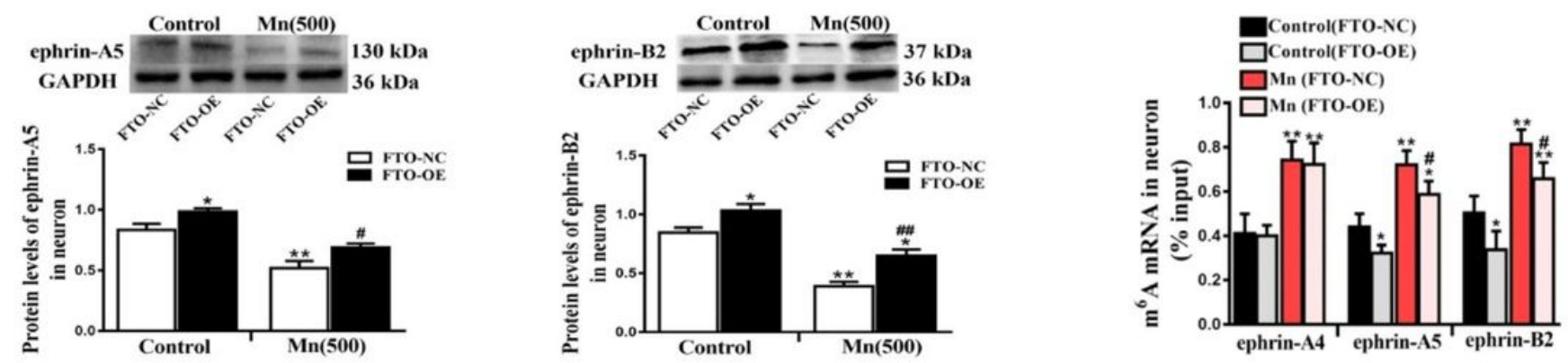

Figure 6

Ephrin-A5 and ephrin-B2 are key target genes for FTO in neuron cells. A-B Expression levels of ephrin-A4/5 and ephrin-B2 in neuron cells determined by real time PCR and immunoblot analysis. C-E Expression levels of ephrin-A4/5, and ephrin-B2 in neuron cells after exposure to $500 \mu \mathrm{M} \mathrm{MnCl} 2$ and/or FTO overexpression. F-H Expression levels of ephrin-A4/5 and ephrin-B2 in neuron cells after exposure to $500 \mu \mathrm{M}$ $\mathrm{MnCl} 2$ and/or FTO over-expression determined by immunoblot analysis. I mRNA m6A levels of ephrin$\mathrm{A} 4 / 5$ and ephrin-B2 in neuron cells after exposure to $500 \mu \mathrm{M} \mathrm{MnCl} 2$ and/or FTO over-expression. Data are expressed as mean \pm S.D. $(n \geq 3) .{ }^{*}<<0.05,{ }^{*} P<0.01$ indicates statistical significance compared with the control (FTO-NC) group; \#P<0.05, \#\#P<0.01 indicates statistical significance compared with the 50 $\mathrm{mg} / \mathrm{kg} \mathrm{MnCl2} \mathrm{(FTO-NC)} \mathrm{group.}$ 


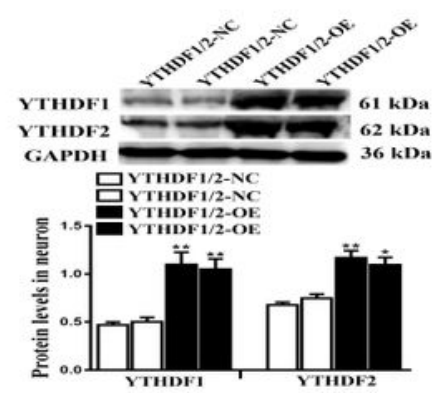

E

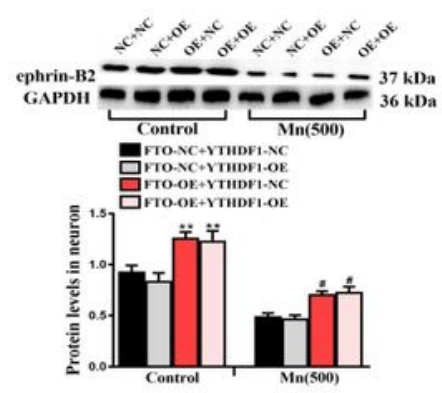

I

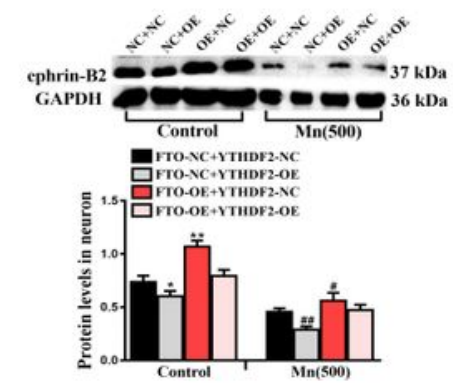

M

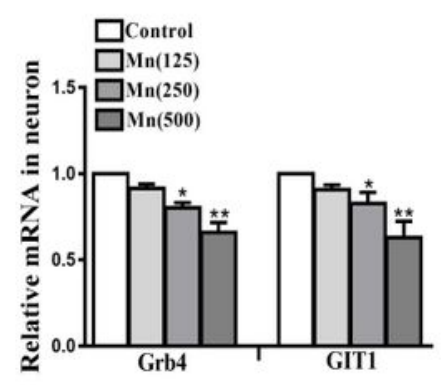

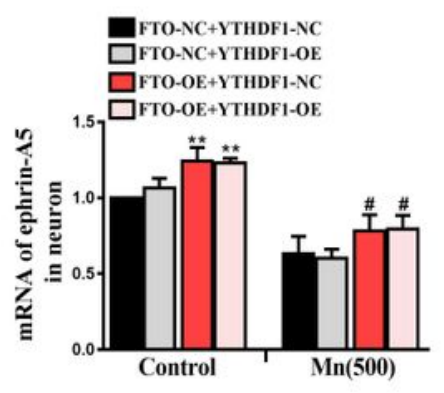

F

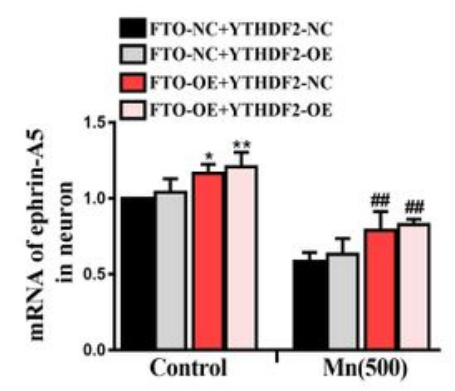

J

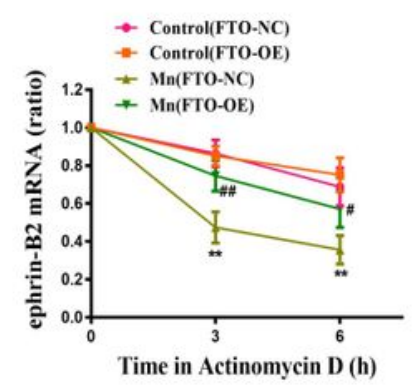

$\mathbf{N}$

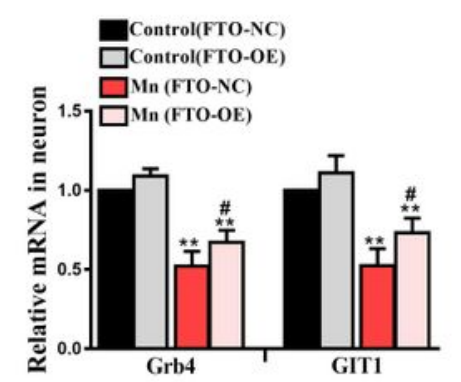

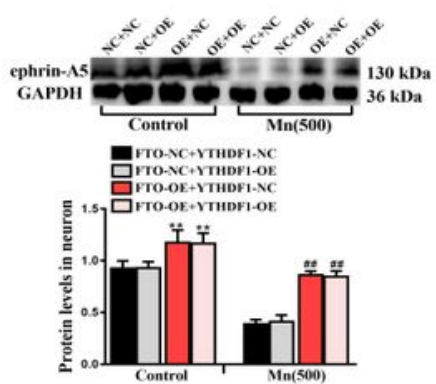

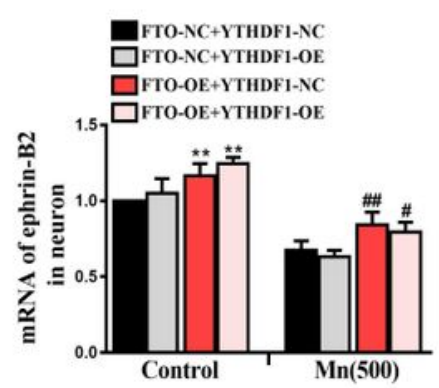

G
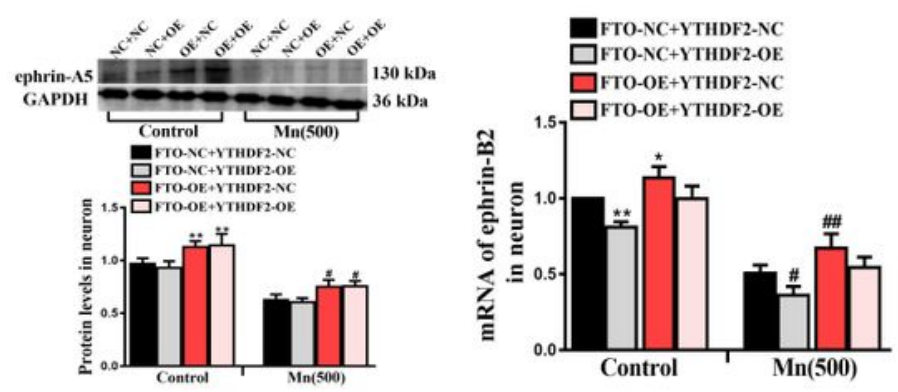

K

L
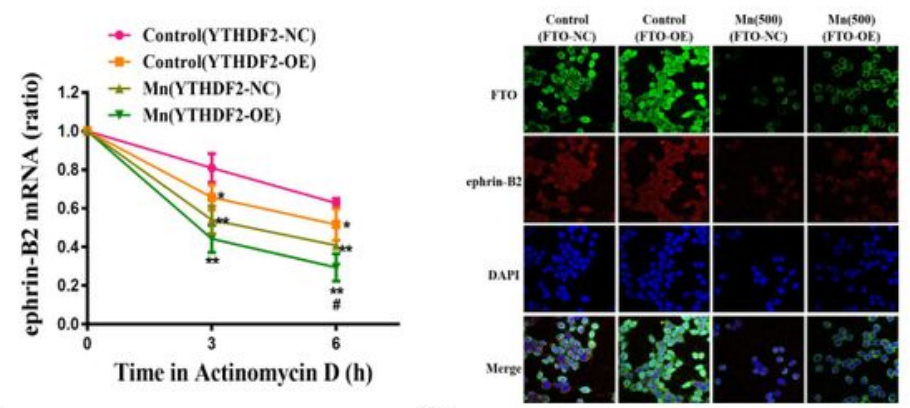

P
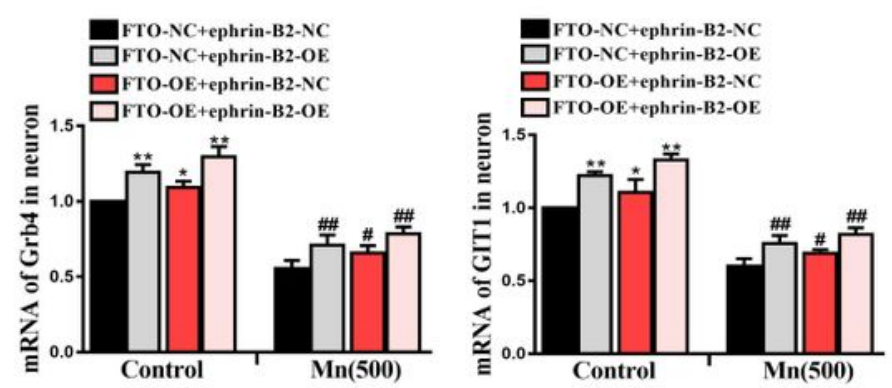

Figure 7

FTO regulates its target genes through m6A/YTHDF2-mediated mRNA decay pathway. A Expression levels of YTHDF1/2 in neuron cells as determined by immunoblot analysis. B-E Levels of ephrin-A5 and ephrin-B2 in cells after FTO and YTHDF1 over-expression. F-I Levels of ephrin-A5 and ephrin-B2 in cells after FTO and YTHDF2 over-expression. J-K RT-qPCR analysis of stability of ephrin-B2 mRNA with FTO or YTHDF2 over-expression. L Immunofluorescence double staining of FTO and ephrin-B2. Nuclei are 
counterstained with DAPI in blue, FTO are counterstained in green, ephrin-B2 are counterstained in red. Scale bar, $100 \mu \mathrm{m}$. M-P Expression levels of Grb4 and GIT1 in neuron cells as determined by real time PCR with or without FTO and ephrin-B2 over-expression. Data are expressed as mean \pm S.D. $(n \geq 3)$. ${ }^{*} P<0.05$, $\star * P<0.01$ indicates statistical significance compared with the control (FTO-NC with or without ephrin-B2NC) group; \#P<0.05, \#\#P<0.01 indicates statistical significance compared with the $50 \mathrm{mg} / \mathrm{kg} \mathrm{MnCl} 2$ (FTO-NC with or without ephrin-B2-NC) group.

A

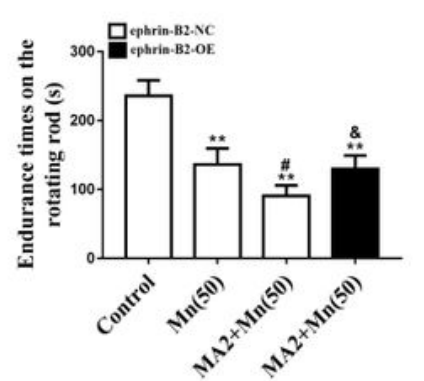

$\mathbf{E}$

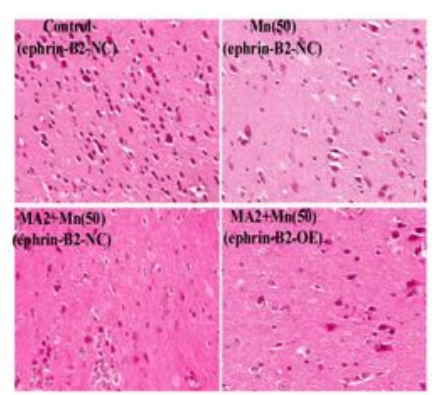

I

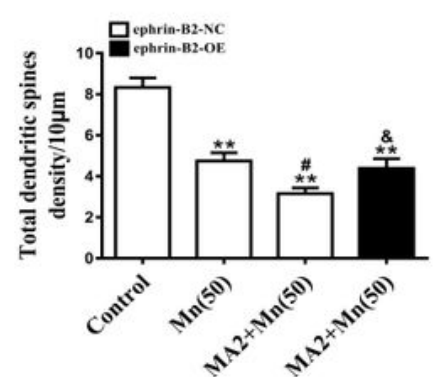

M

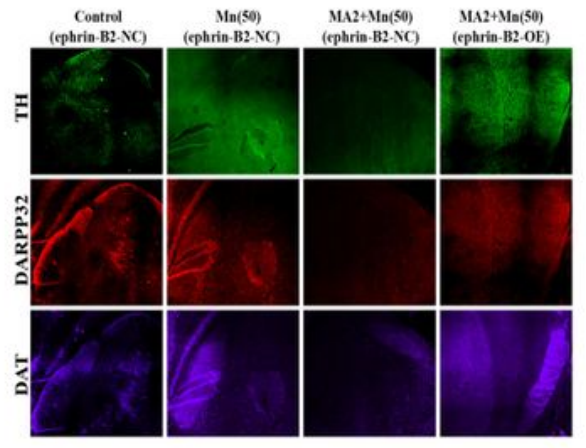

B

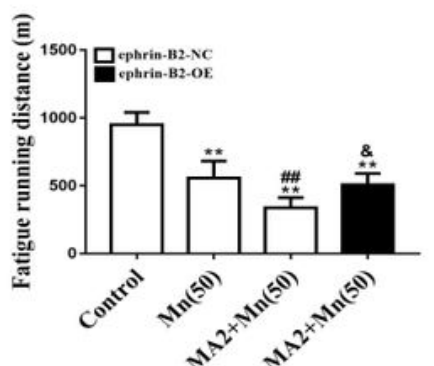

F

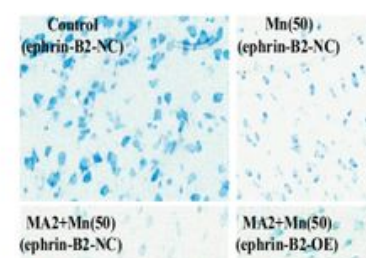

J

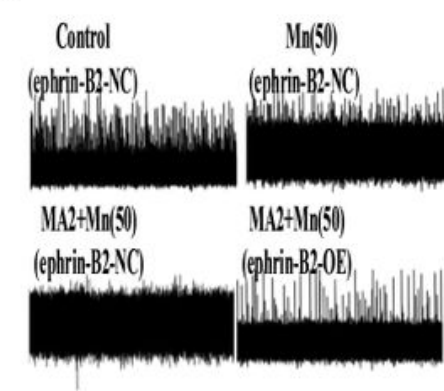

N
C

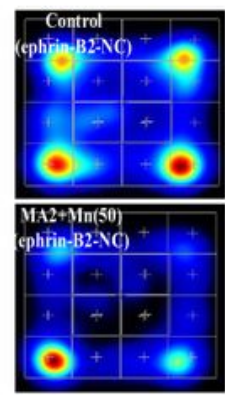

G

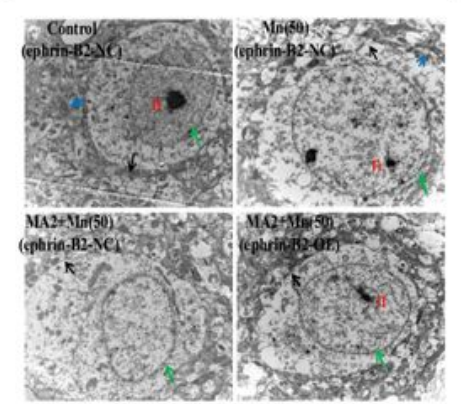

K
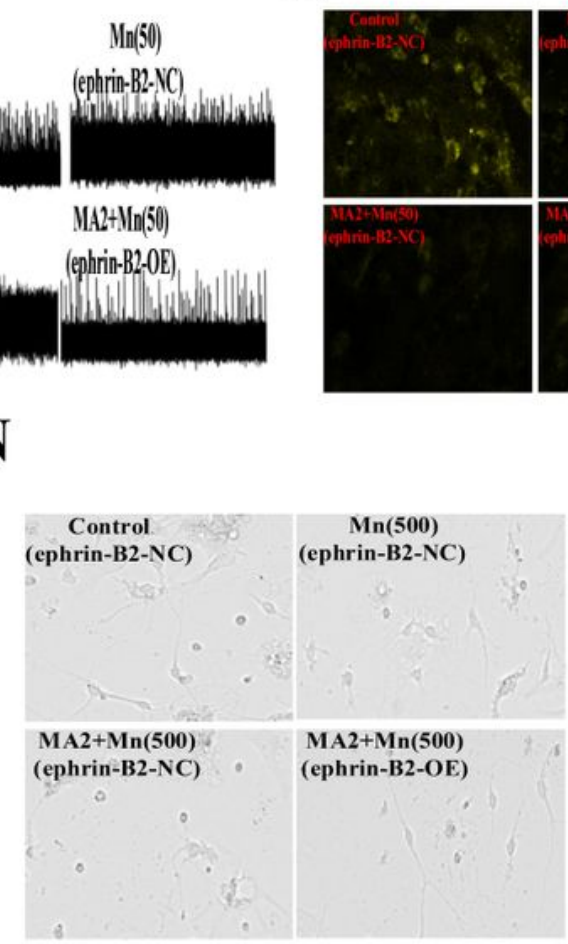

D
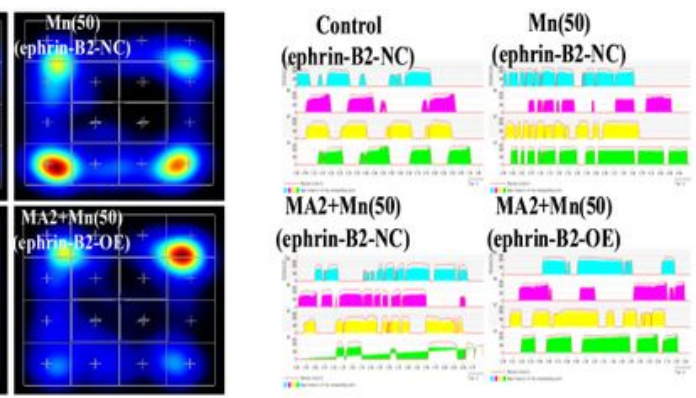

H

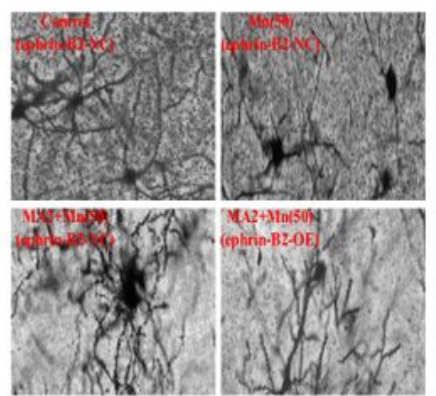

L
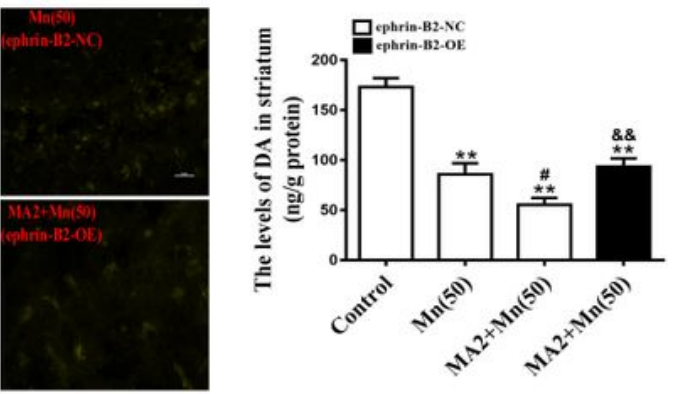

O

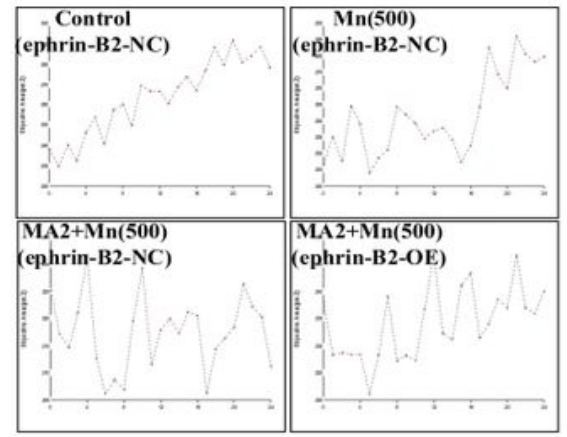


Selective ephrin-B2 activation in the striatum rescues defects in motor function. A Endurance times on the rotating rod with inhibition of FTO activity in combination with activation of ephrin-B2. B Fatigue running distance in the fatigue meter. $C$ Heat map of activity in the open field. D Mean intensity in the gait tests. $E$ HE staining of striatum. F Nissl staining of striatum. G Electron microphotograph of striatum. Green arrow-heads represent the nuclear membrane, $\mathrm{n}$ representative nuclei, blue arrow-heads represent mitochondria, black arrows represent endoplasmic reticulum.. H-I Golgi-Cox staining of striatum. J Trace representative spontaneous firing recorded by MED64. K Retrograde labeling of nigro-striatal projection neurons with FG. L DA levels of striatum. M The immunofluorescence triple staining of TH, DARPP32 and DAT. TH are counterstained in green, DARPP32 are counterstained in red, and DAT are counterstained in purple. $\mathrm{N}-\mathrm{O}$ Observe the changes of neuronal axons growth with live cell station. The magnification of the sections stained with HE, Nissl, FG and Golgi-Cox was $\times 400$. The magnification of the electron microphotograph was $\times 4,000$. Data are represented as mean \pm S.D. $(n \geq 3) .{ }^{*} P<0.05,{ }^{*} P<0.01$ indicates statistical significance in contrast with the control (ephrin-B2-NC) group; \#P<0.05, \#\#P<0.01 indicates statistical significance in contrast with the $50 \mathrm{mg} / \mathrm{kg} \mathrm{MnCl} 2$ (ephrin-B2-NC) group. \& $\mathrm{P}<0.05, \& \& \mathrm{P}<0.01$ indicates statistical significance in contrast with the $20 \mathrm{mg} / \mathrm{kg} \mathrm{MA2}+50 \mathrm{mg} / \mathrm{kg} \mathrm{MnCl} 2$ (ephrin-B2-NC) group.

\section{Supplementary Files}

This is a list of supplementary files associated with this preprint. Click to download.

- Graphicalabstract.jpg

- Supplementarydata.docx 